\title{
Minimally Invasive Extreme Lateral Trans-Psoas Approach to the Lumbar Spine: Applications and Techniques
}

\author{
Brian Hood and Steven Vanni \\ University of Miami, Miller School of Medicine, \\ Jackson Memorial Hospital, Miami, FL
}

USA

\section{Introduction}

The biomechanical advantages to a load sharing anterior lumbar construct have not been debated. The development of a technique to place such a construct has gone through an evolution through PLIF, to open ALIF, to endoscopic ALIF. Recently the technique of a direct lateral mini-open approach has been popularized through the development of better retraction, improved visibility, and superior results. In the following chapter, we describe the technique, the indications, and the potentials for complications that surgeons need to comprehend before employing this powerful tool.

\section{History}

Historically, spine surgery was performed through a posterior approach as it was the most direct pathway to the bony structures. Anterior approaches to the spine were initially developed in response tuberculosis. An anterior approach to the treatment of spondylolisthesis was first reported by Burns in 19331. Since its first description, anterior lumbar interbody surgery has been used for the treatment of spinal deformity, spinal instability, tumors, infection and chronic low back pain including "failed back syndrome" $2-4$ In 1953 Cloward 5 described performing an interbody fusion from a posterior approach which allowed a complete decompression of the neural elements as we as performing a 360 degree fusion without violating the abdominal viscera and retroperitoneal structures.

In the 1970's , despite satisfactory results from multiple authors, the anterior approach was condemned for causing undue surgical trauma to the patient with a considerable complication rate as well as postoperative morbidity 6 .

The laproscopic ALIF was developed as a minimally invasive alternative to the traditional ALIF and mini-open ALIF and has been reported to be a safe surgical procedure? Laparoscopic procedures still share some complications of open surgery such as great vessel injury, retrograde ejaculation, and arterial thromboembolism 8-10. In addition to the morbidity of open anterior surgery, laparoscopy introduces its own set of challenges such as bowel injury during the percutaneous approach, $\mathrm{CO} 2$ insufflation leading to low cardiac 
output 11 . In addition, depth perception is compromised with two dimensional imaging and most neurosurgeons are unfamiliar with the use of laparoscopic instruments. Regardless of mini-open or laparoscopic, access to the anterior lumbar spine is still dependent on a competent general or vascular surgeon. Biomechanical insufficiency of the ventral lumbar spine is still a common clinical problem for spine surgeons and the ability to access and intervene is an important tool in ones surgical armamentarium.

In searching for ways to improve patient care and reduce operative morbidity there have been many significant improvements in instrumentation and technique. Minimally invasive techniques have evolved over the ensuing decade and now encompass all aspects of lumbar spine surgery. The advantages of minimal access surgery include minimal tissue disruption leading to a decrease in postoperative pain and more rapid post operative mobilization. In addition, decreased disruption of the paraspinal muscles and ligaments allows for proper maintenance of spinal biomechanics. Advances in retractors and instrumentation allow direct access to the site of pathology decreasing the size of exposure for many procedures.

The anterolateral approach first reported for the treatment of Potts disease was adapted to the treatment of throacolumbar fractures by McAfee ${ }^{12}$. Mayer reported a minimally invasive retroperitoneal microscopic approach for access to L2-L5 in patients having undergone previous posterior procedures ${ }^{13}$. McAffe later reported an endoscopic procedure that involved balloon dissection of the retrotransversalis fascia and allowed placement of an interbody device ${ }^{14}$.

The application of tubular retractors to lumbar surgery contributed significantly to the advancement of minimally invasive spinal surgery. In 1998, the METRx-MD (Medtronic Sofamor Danek, Memphis, TN) was introduced allowing the use of the intraoperative microscope in addition to the edoscope. The fixed tube was modified to a split blade design that could accommodate a microscope, or by the use of fiberoptic light, loupe magnification.

Bergey reported an endoscopic transpsoas approach for the treatment of degenerative scoliosis ${ }^{15}$. Pimenta described a minimally invasive transpsoas retroperitoneal approach using tubular retractors, and in doing so allowed spine surgeons to have access to the power of an anterior approach through a minimally invasive route that didn't require an access surgeon ${ }^{16}$.

The XLIF approach to the anterior spinal column has some distinct advantages over traditional anterior and posterior approaches.

- A true minimally invasive approach involving minimal disruption of tissues resulting in less blood loss, decreased postoperative pain, and a shorter recovery time.

- $\quad$ Surgical exposure is adequate, safe and reproducible.

- Avoids disruption, destruction, and denervation of posterior musculature.

- Preserves the posterior ligamentous complex (PLC) allowing preserved anatomical load sharing, motion coupling, stability, and facilitates alignment and decompression via ligamentotaxis.

- Avoids iatrogenic instability via resection of the posterior bony elements.

- Decreased risk of vascular injury.

- Surgical access to the disc space allows for a thorough disc removal and endplate preparation.

- Maximized access to the ring apophysis supporting axial and coronal deformity correction and facilitation of alignment. 


\subsection{Biomechanics, indications and contraindications}

Biomechanically, the lateral interbody fusion is a minimally invasive, muscle and ligament sparing procedure that allows preservation of the spine's inherent biomechanical stabilizers. Anterior column fusions provide a superior biomechanical environment for fusion. White and Panjabi evaluated the spinal ligamentous tensile strength and found the ALL to be the strongest ligament in the spine ${ }^{17}$. The biomechanics of a construct not only reflect the construct itself, but the approach to implant the construct. The traditional ALIF resects the ALL, and the PLIF and TLIF resect a varying degree of the posterior elements. The size or "footprint" of the interbody implant as well as its position within the interspace also influences the biomechanics of the construct. The large lateral interbody spans the ring apophysis and provides maximum vertebral support.

The surgical indications for the extreme lateral interbody fusion is essentially any thoracolumbar case above L5-S1 requrinig access to the disc space and/or vertebral bodies. We will focus more on individual pathologies throughout the chapter, but as an overview:

- $\quad$ Degenerative disc disease (DDD) with instability.

- The benefits of using an extreme lateral interbody fusion for DDD include stabilization of the affected level with restoration of the disc space height. In doing so, an indirect decompression of the neural foramina is seen as restoring the disc height leads to significantly increased foraminal volume.

- Recurrent disc herniation.

- Using a lateral access corriodor allows the surgeon to avoid scar tissue, adequately decompress the neural elements, and perform a fusion all through a minimal access corridor.

- Degenerative spondylolisthesis.

- Because the anterior and posterior longitudinal ligament remain intact, listhesis can be relieved through ligamentotaxis. In addition, because of the exposure obtained through a lateral portal, a much larger interbody graft can b e placed thatn those used with standard posterior lumbar interbody (PLIF) or transforaminal lumbar interbody fusion (TLIF).

- Degenerative scoliosis.

- Extreme lateral trans-psoas approach is able to provide the benefits of both the ALIF and PLIF/TLIF techniques and minimize the negative aspects.

- Pseudoarthrosis

- The lateral access corridor minimizes dissection through previous scar tissue and allows the placement of a large interbody graft under compression allowing for improved stability after a failed posterior fusion.

- Discitis, Osteomyelitis.

- The exposure provide allows for a thorough discectomy and cleaning of the endplates.

- Total disc replacement (TDR)revision

- Lateral access allows a large TDR implant to be removed without compromising the neural elements or having to reexplore the anterior exposure at levels above L5S1.

- Post laminectomy instability, deformity 
- Iatrogenic deformity created by multilevel laminectomies is an ideal situation for lateral access for correction of the deformity through restoration of anterior height, providing a stable fusion, as well as avoiding complications of revision surgery.

- Junctional disease

- We frequently employ the Lateral route for patients who have failed either above or below previous constructs.

Several limitations merit discussion prior to considering a lateral approach to pathology.

- Anomalous vascular anatomy interfering with the lateral approach.

- When dealing with idiopathic scoliosis with severe rotational deformities, the coronal and saggital rotations may lead to vascular structures impeding lateral access. Careful scrutiny of preoperative MRI is imperative to preventing complications.

- Bilateral retroperitoneal scarring.

- A history of nephrectomy or other retroperitoneal surgery precludes safe access on the side of previous pathology. A history of anterior lumbar interbody fusion (ALIF) or previous lateral approach are not absolute contraindications to lateral access.

- $\quad$ Degenerative spondylolistheis of grade III or greater.

- In high grade spondylolisthesis the exiting nerve root is located in a more anterior position. In addition, it is difficult to find the anatomical center to place the interbody graft.

- Cannot access L5-S1

- Some surgeons will resect a portion of the iliac crest, in general though, the L5-S1 level is best addressed with a PLIF/TLIF.

- $\quad$ Renal cysts, or the presence of a horseshoe kidney may preclude lateral access.

\subsection{Anatomy}

The retroperitoneal space is the area of the posterior abdominal wall located between the posterior parietal peritoneum and the posterior part of the transversalis fascia (Figure 1). The adrenal glands, kidneys and ureters are located in the retroperitoneal space as well as lumbar plexus, the aorta, and the inferior vena cava and their tributaries.

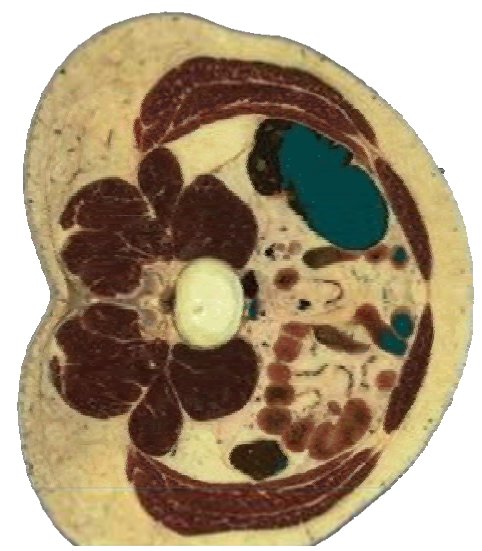

Fig. 1. Axial illustration of patient oriented for retroperitoneal transpsoas access to the lumbar spine. 


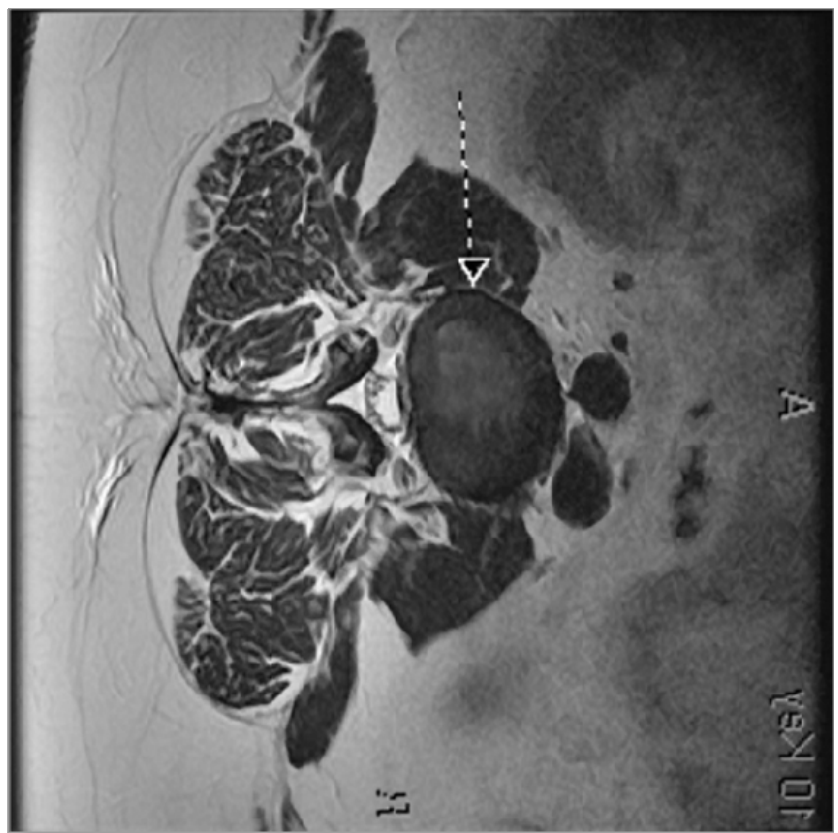

Fig. 2. MRI oriented in anatomical position for retroperitoneal transpsoas access to the lumbar spine.

The anterior and lateral abdominal muscles include the obliques (external and internal), the transverses abdominis, and rectus abdominus. After dissection through the skin and subcutaneous tissue, the first muscular layer, and most superficial is the external oblique. After passing through the external oblique, the next muscle encountered is the internal oblique. The only two structures passing through the internal and external oblique muscles are the iliohypogastric and illioinguinal branches of L1, both are purely sensory brances. Immediately under the internal oblique is the transversalis muscle. The final muscle transvered during the approach is the psoas major. The muscle originates from tendinous arches between vertebra diminishing in size as it traverses the pelvic brim, and fuctions as a hip flexor, abductor and lateral rotator. The lumbar plexus lies within the substance of the psoas major (Figure 2 with arrow passing through the psoas major). The genitofemoral nerve can be visualized on the anterior surface of the muscle.

Four paired lumbar arteries emerge from the posterior aspect of the aorta (Figure 3). The venous supply runs with the arteries draining into the vena cava. The bifurcation the aorta and vena cava into the common iliac vessels generally occurs around the L4-5 disc space. Targeting the center of the disc space generally avoids contact with the anteriorly placed vasculature. The location of blood vessels is shown below (Figures 4-7). 

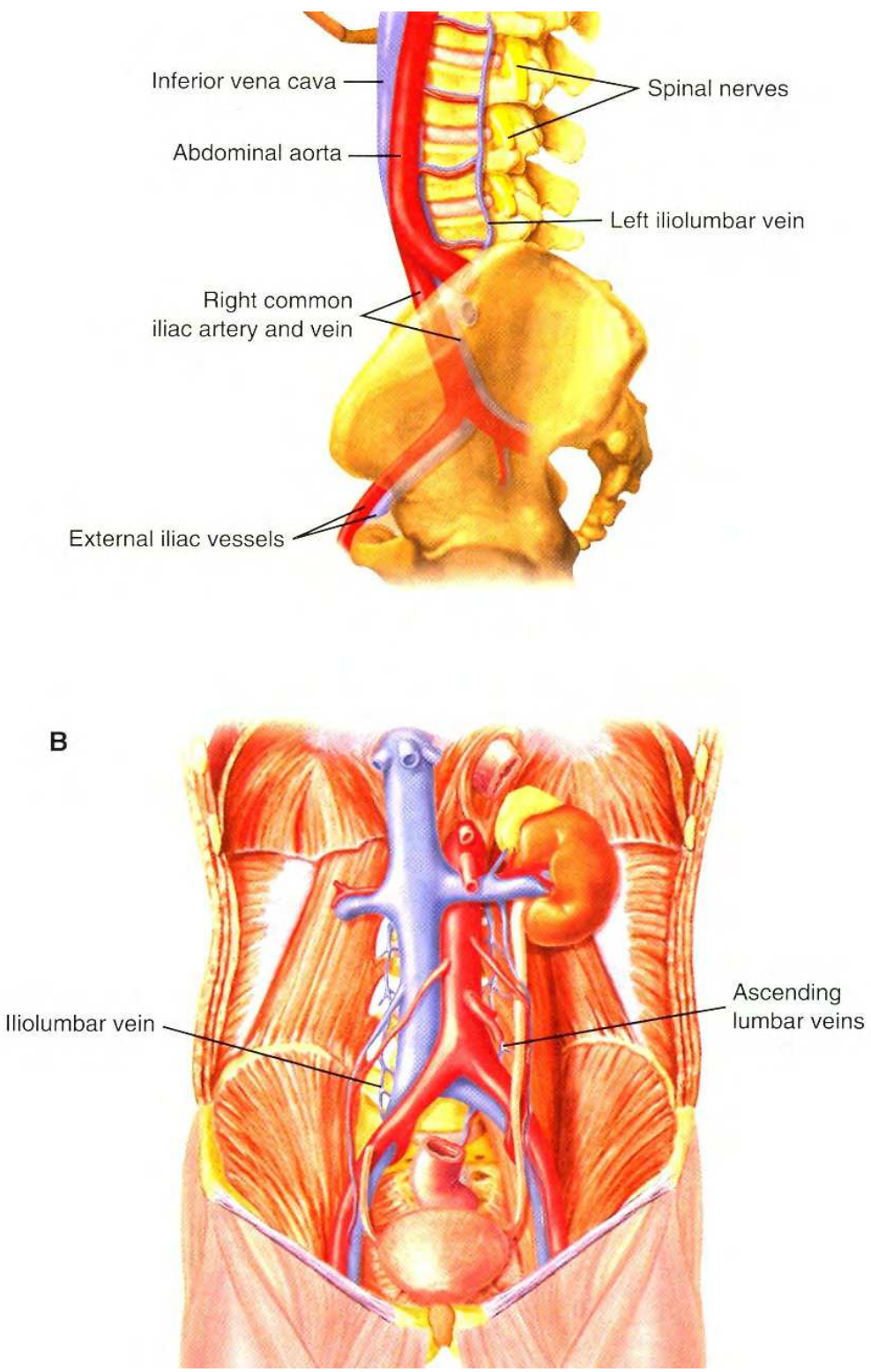

Fig. 3. The major lumbar vasculature. 
Minimally Invasive Extreme Lateral

\section{L1-2 BLOOD VESSEL LOCATIONS}

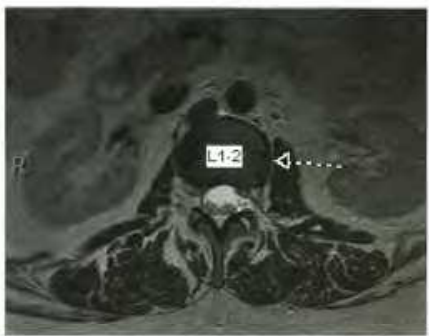

RT

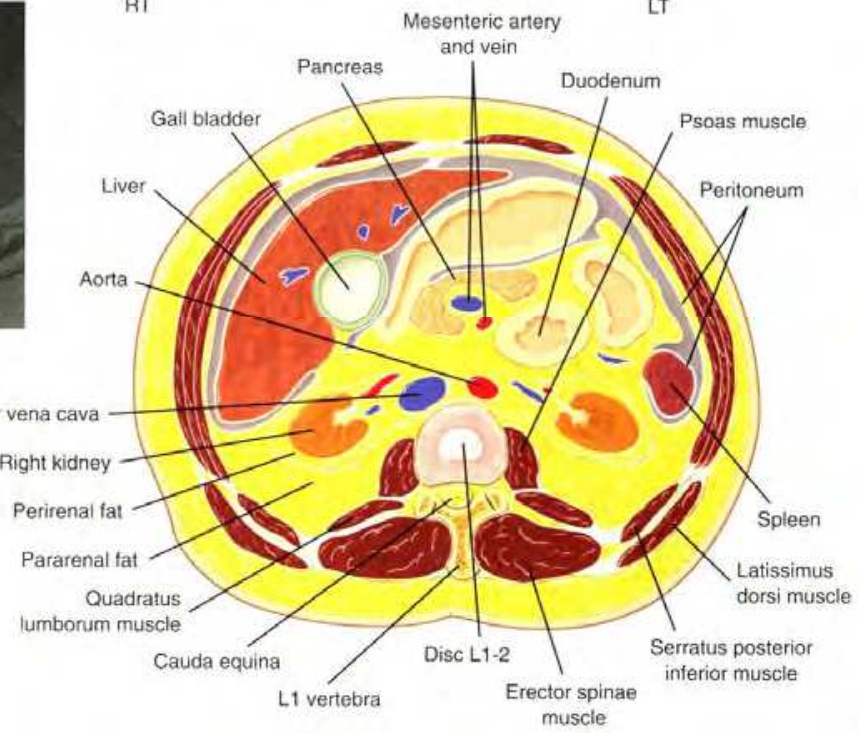

Fig. 4. L1-2 Blood vessel locations.

\section{L2-3 BLOOD VESSEL LOCATIONS}

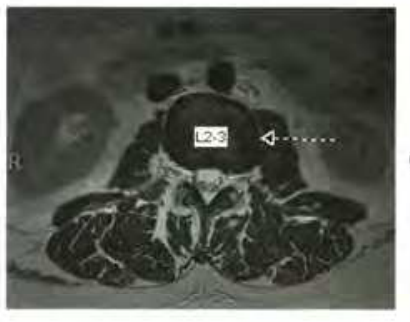

RT

LT

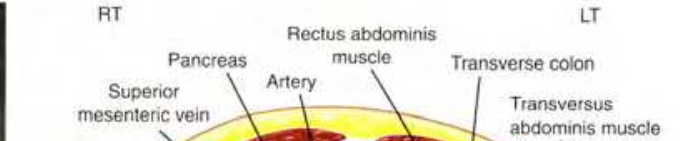

Gall bladder

abdominis muscle

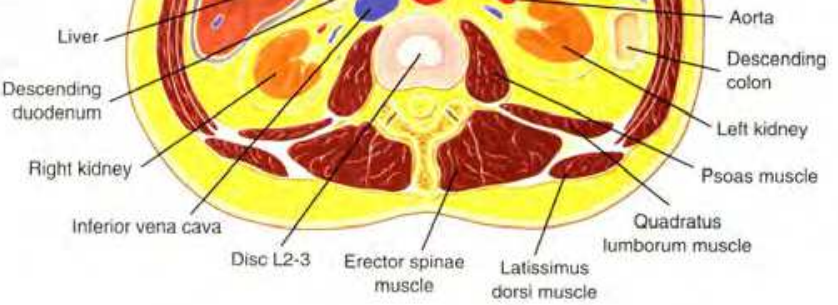

Fig. 5. L2-3 Blood vessel locations. 


\section{L3-4 BLOOD VESSEL LOCATIONS}

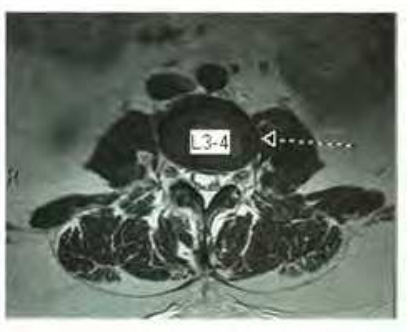

RT

LT
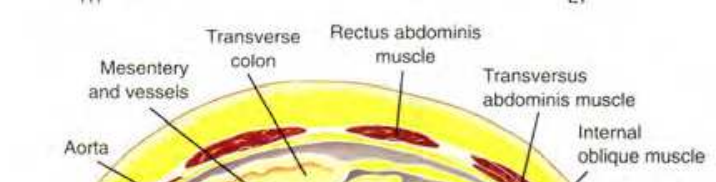

External

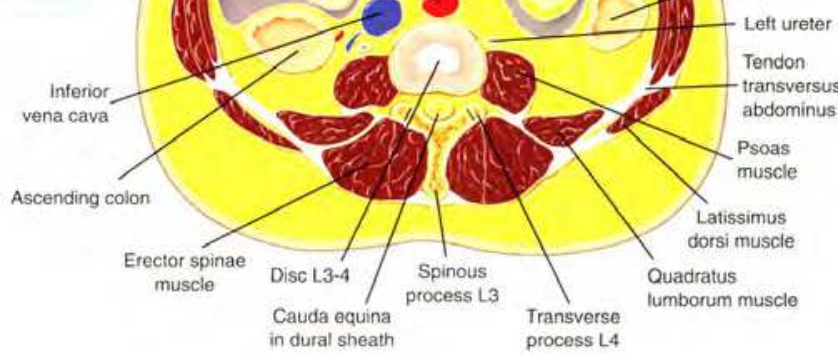

Fig. 6. L3-4 Blood vessel locations.

\section{L4-5 BLOOD VESSEL LOCATIONS}

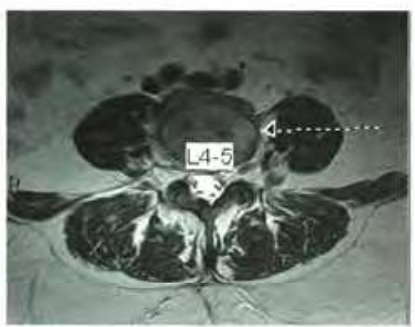

RT

LT

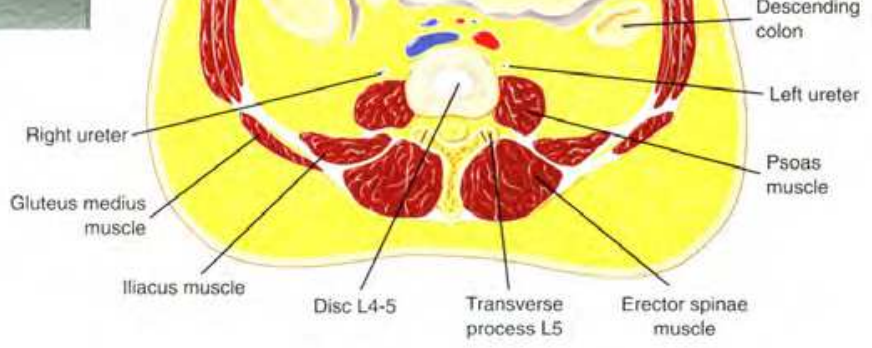

Fig. 7. L4-5 Blood vessel locations. 
The Lumbar Plexus

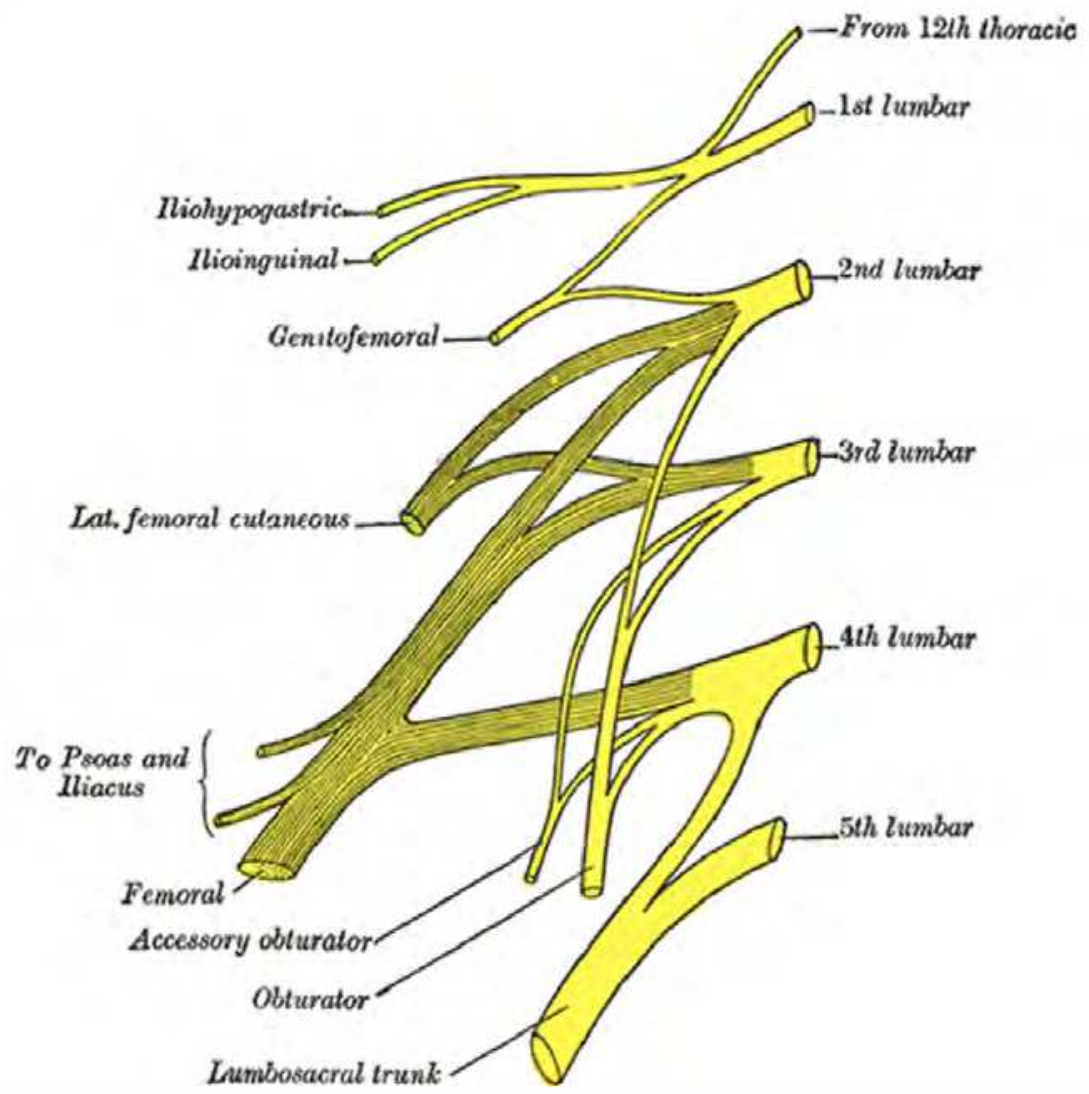

Fig. 8. The lumbar plexus.

The lumbar plexus is formed by the ventral rami of the first three lumbar roots and part of the foruth root and is generally located in the posterior substance of the psoas muscle (Figure 8). L1 gives off the iliohypogastric and ilioinguinal nerves which travel superficially through the retroperitoneal space and then pass to run between the internal and external obliques and supply sensation to the groin. L1 and L2 both contribute to the genitofemoral nerve which lies on the anterior fascia of the psoas muscle and provides sensation to the genital and femoral regions. L2 and L3 give rise to the lateral cutaneous nerve of the thigh wich innervates the anterolateral and lateral surfaces of the thigh. The large femoral nerve receives contributions from L2, L3 and L4 lies within the psoas muscle and innervates the quadriceps muscles. The obturator nerve innervates the adductor muscles of the thigh and provides cutaneous sensation to the inner thigh and receives contributions from L2, L3, L4 and exits at the medial border of the psoas and crosses the sacral ala. 
In an anatomic survey, Benglis et al sought to delineate the location of the lumbar contributions to the lumbosacral plexus in relation to the respective disc spaces relevant to the transpsoas approach as seen via fluoroscopic imaging (L1-5)( Figures 9-11). The findings of their study suggested that the lumbosacral plexus migrates from a dorsal to ventral location from the L1 through the L5 disc spaces. Therefore, when targeting the center of the disc space for an extreme lateral procedure, the neural structures are at greatest risk of injury at the L4/5 level with a posteriorly positioned dilator or retractor. They also concluded that the risks of injuring inherent motor nerve branches directed to the posas muscle still exists even with neuromonitoring as well as injury to the genitofemoral nerve which pierces the psoas muscle and travels caudally on its ventral surface (at L1-2) supplying sensory innervations to the femoral triangle and creamasteric muscles in males).

Moro et al studied the configuration of the lumbar plexus in regard to the safety of the endoscopic transpsoas approach. After identifying the anterior and posterior borders of the vertebral body, they divided them into zones with zone 1 located anteriorly and zone IV located adjacent to the posterior margin of the vertebral body. They found that the most anterior position of the nerve was zone III and this was found at L4/5, and concluded that the safety zone should be L4/5 and above.

To prevent lumbosacral plexus injury a thorough understanding of the neural anatomy at various disc levels is essential. In addition, intraoperative monitorin is used. This includes free-run EMG and dynamic triggered EMP. This provides real time nerve proximity measurements that are critical to avoiding nerve injury during the transpsoas approach.

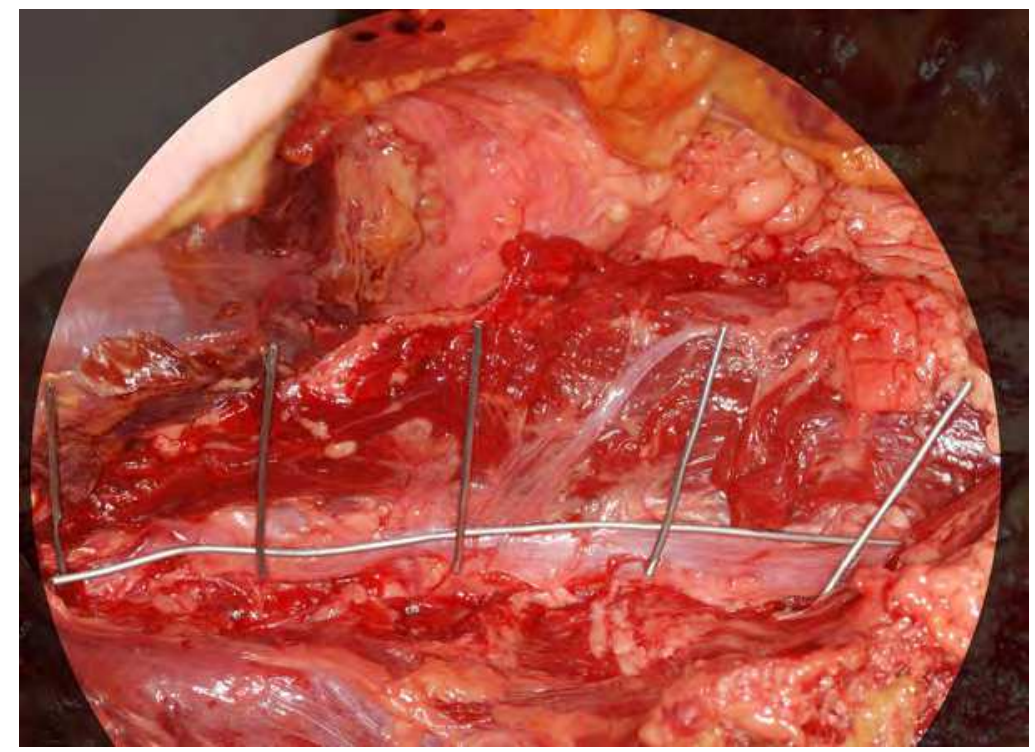

Fig. 9. Anatomical dissection with radiolucent markers placed on femoral nerve and over disc spaces. 


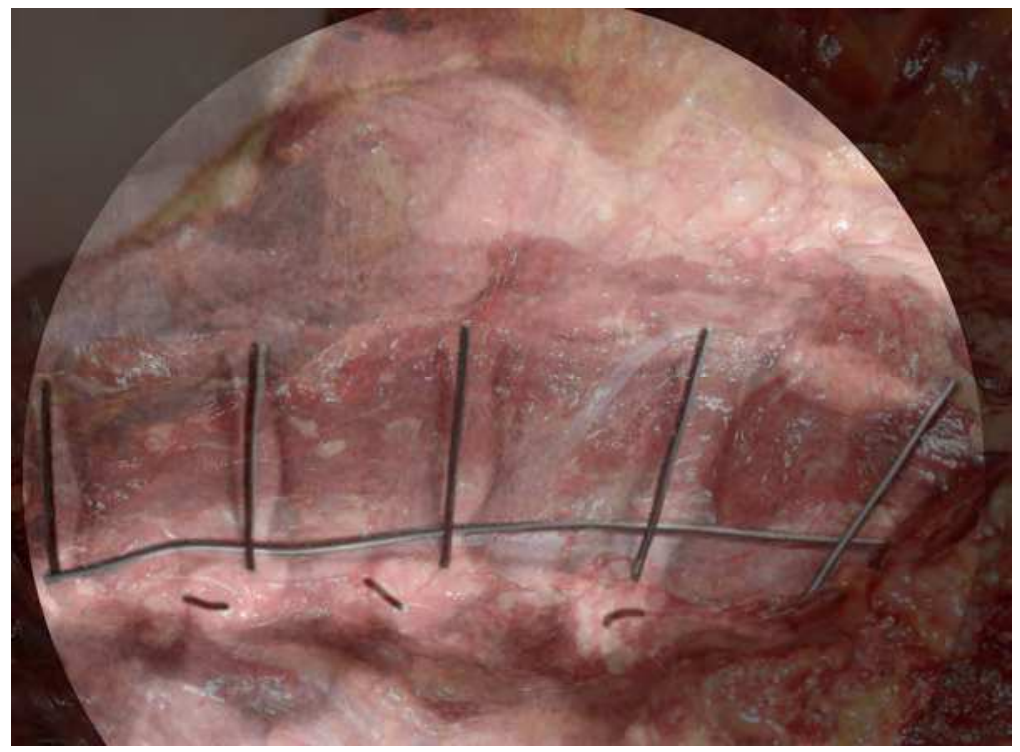

Fig. 10. Anatomical dissection with musculature removed with radiolucent markers over femoral nerve and disc spaces.

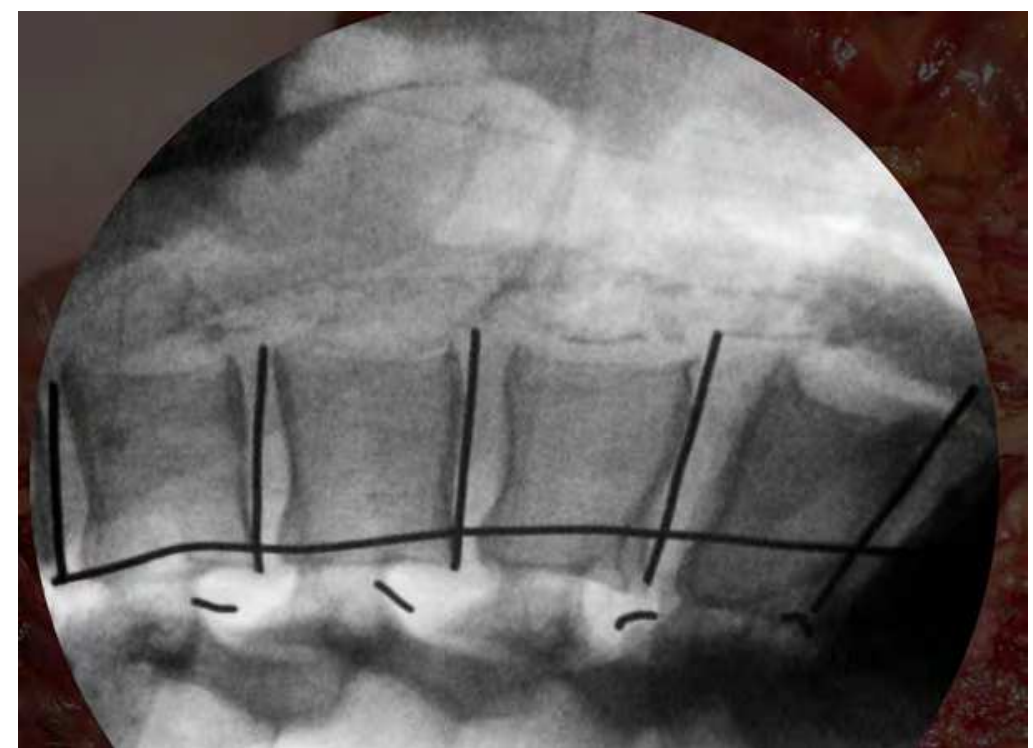

Fig. 11. Radiograph of anatomical dissection with radiolucent markers over the femoral nerve, the disc spaces, and in the respective foramen. 


\subsection{Summary}

- $\quad$ The lumbar plexus was found within the psoas muscle lying predominately in a cleft at the junction of the transverse process and the vertebral body.

- There was a dorsal to ventral migration of the plexus in the lateral fluoroscopic view from L1 to L5.

- The plexus below L5 continued as the femoral nerve.

- The dilators and retractor should pass through the anterior portion of the psoas muscle and lie on the middle to anterior portion of the disc space.

- This is most relevant to the lateral approach at L4/5 (Figure 12).

- The use of free run EMG and discreet dynamic triggered EMG is essential, but its use can still result in nerve injury from compression via the retractor.

- The risk of sensory nerve injury is still present during this approach.

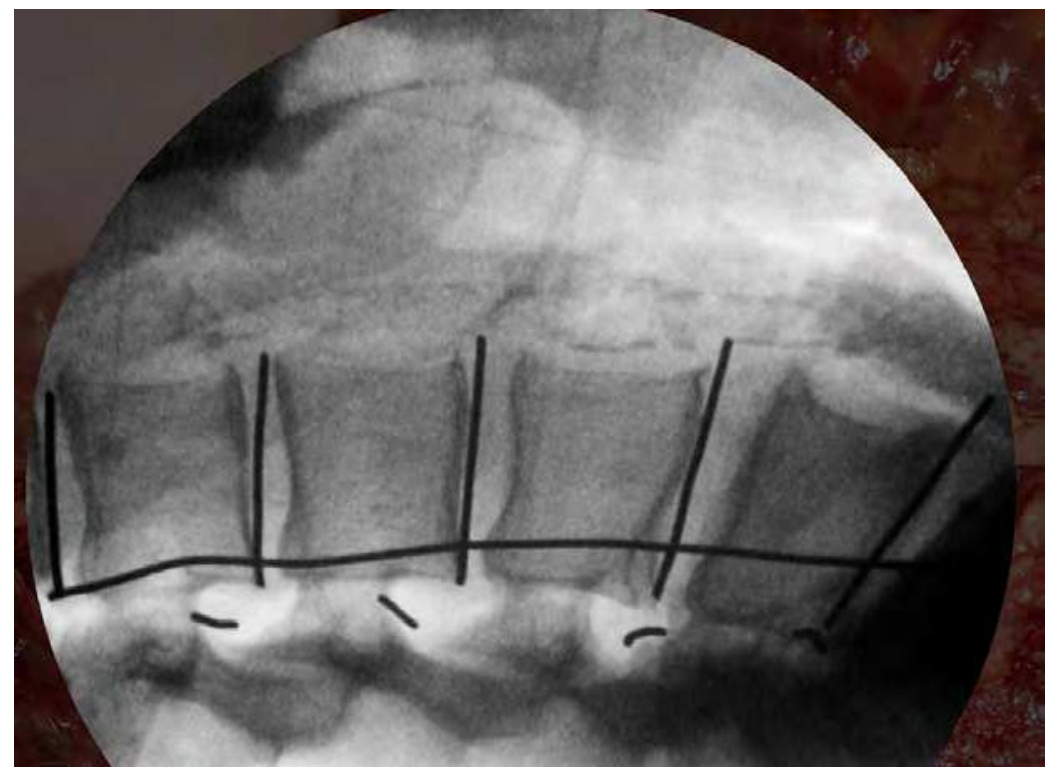

Fig. 12. Illustration of the risk of femoral nerve injury when attempting an L4-5 or L5-S1 lateral interbody fusion.

\subsection{The approach}

Performing a successful transpsoas procedure starts with the patient positioning and ensuring that adequate radiological visualization is possible. The operative table must be converted to the "reverse" orientation by replacing the head piece from the end above the base to the opposite side (Figure 13). 


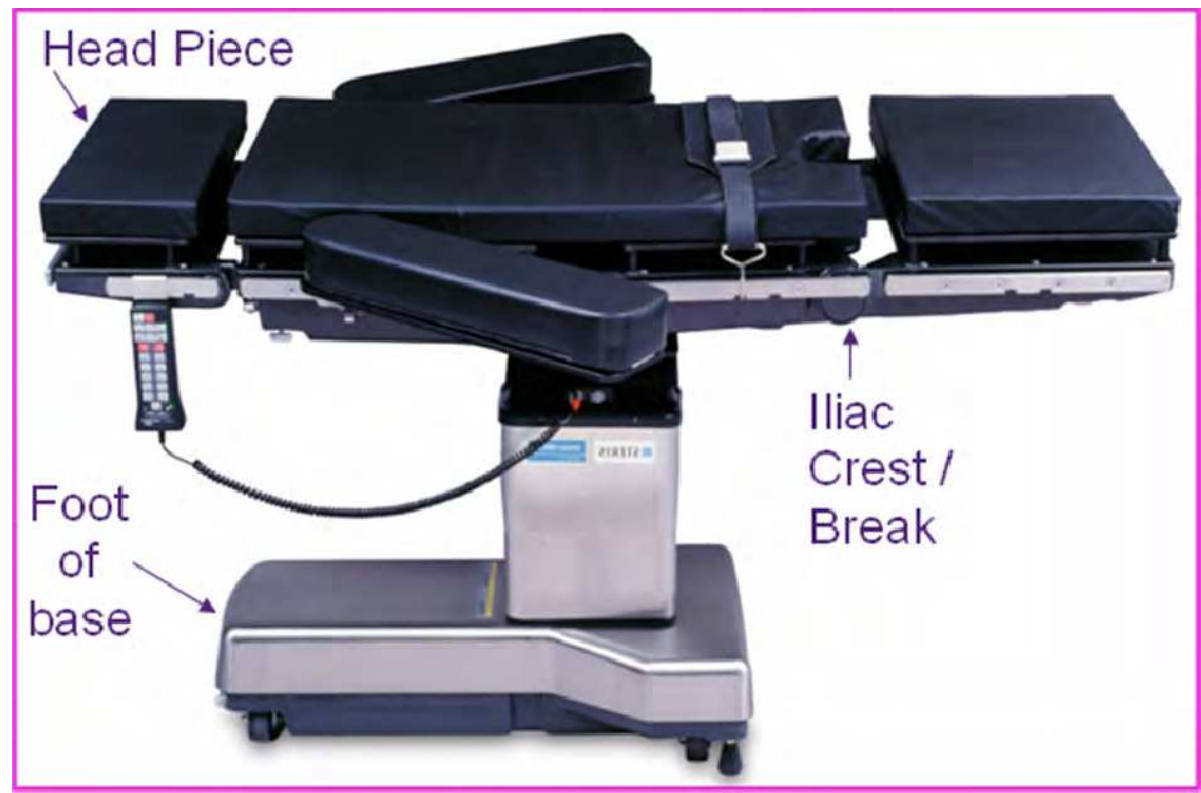

\section{"Normal" table position: notice head piece over foot of base}

Fig. 13. Standard orientation. To facilitate an successful lateral retroperitoneal transpsoas approach, the head piece must be switched.

Prior to positioning the patient, a left sided or right sided approach should be chosen considering the following factors.

- Previous unilateral retroperitoneal surgery.

- Position of iliac crest in relation to targeted disc space on pre operative plain films.

- Collapsed or open disc space, presence of lateral listhesis.

- In cases of degenerative scoliosis, convex or concave aspect of curve.

- Convenience of operating room set up.

- Vascular anomalies present on preoperative MRI that would preclude access.

In general, we typically chose a left sided access approach in most instances when all other variable have been accounted for to avoid vasculature and for convenience of OR setup.

The patient is then placed in the lateral position with an axillary roll and with all pressure points securely padded (Figure 14). The table should initially be flat and radiographs need to be obtained in a true lateral and AP plane during positioning prior to taping the patient into position. 


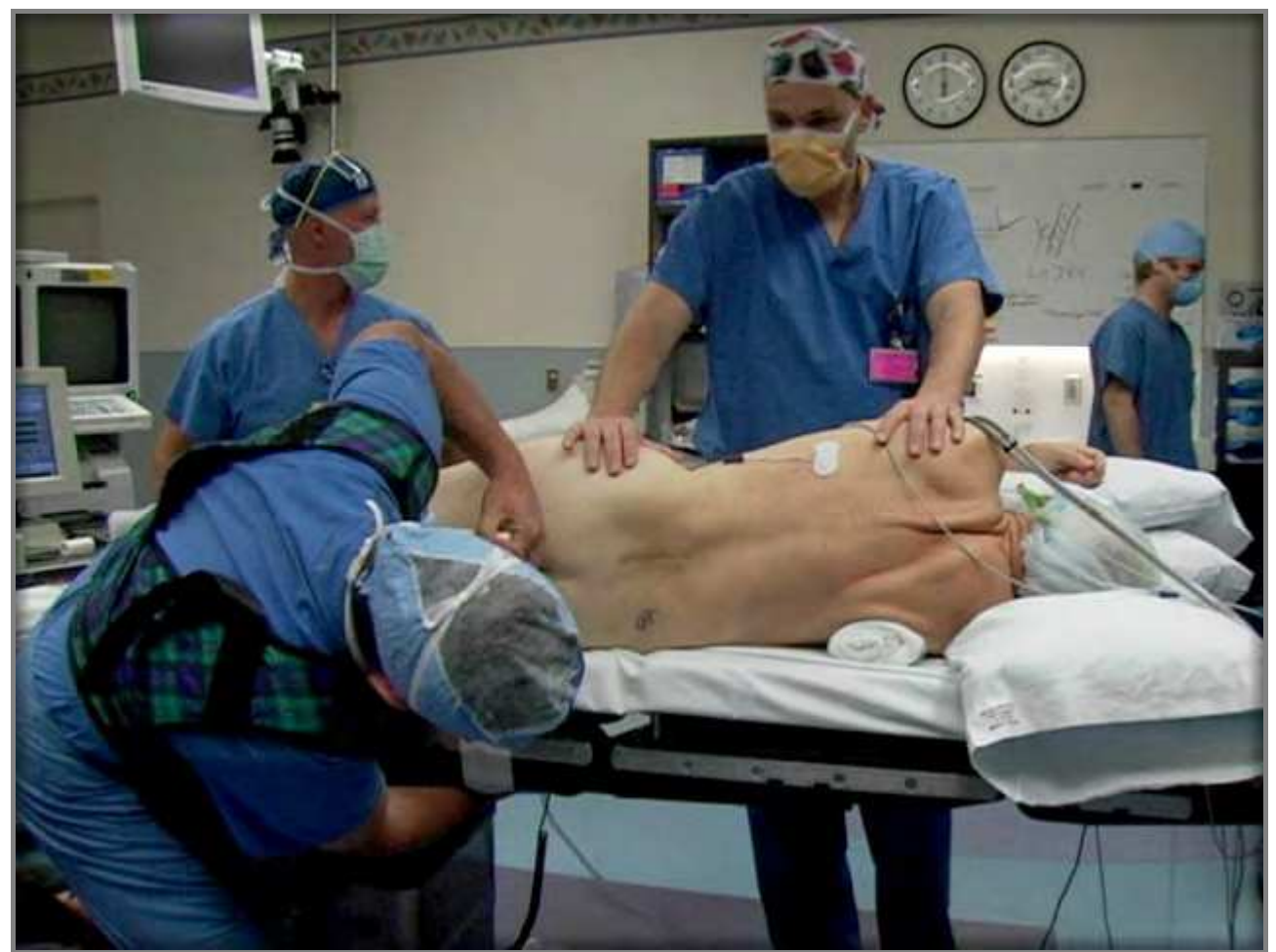

Fig. 14. Proper positioning of patient prior to taping and "breaking" table. The patient is then secure to the table at the following locations: just below the iliac crest (A), over the thoracic region (B), from the iliac crest to the knee, then to the table (C), from the table to the knee, past the ankle, then to the table (D) (Figure 15).

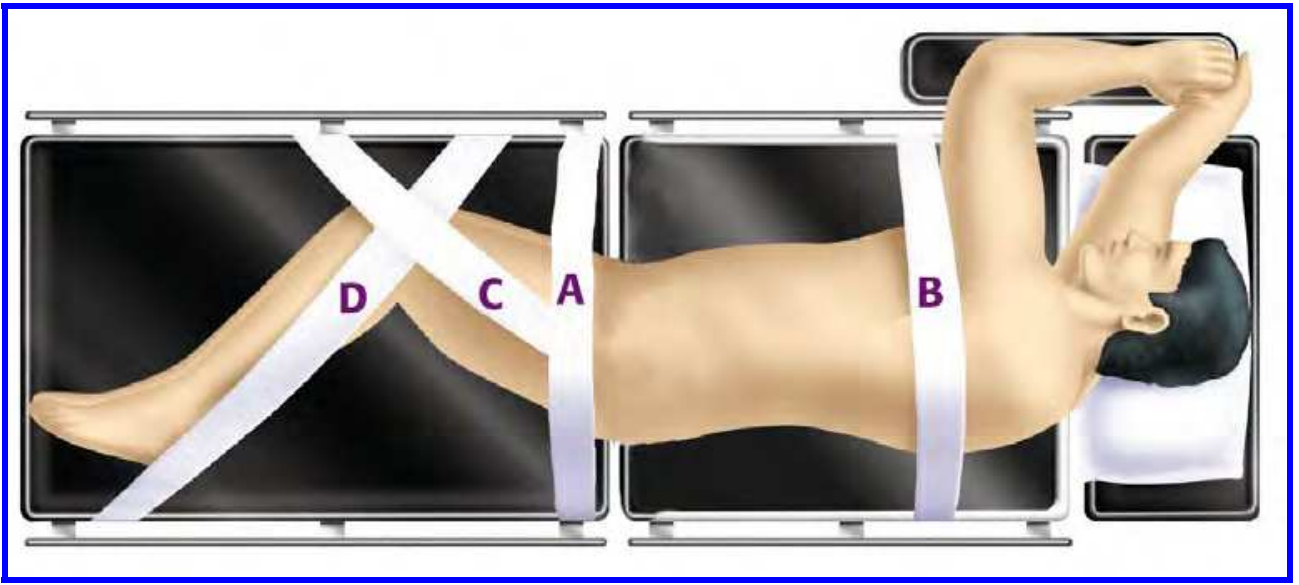

Fig. 15. Diagram showing correct placement of tape. 
Next, the C-arm fluoroscopy unit is brought into the field and AP images are first obtained. In order to obtain the true images (Figure 16), the c-arm must match the lordotic angles of the spine. It is important at all times to maintain the fluoroscope at 90 degrees to the patient while rotating or tilting the table to obtain a true view. Indicators of a true AP image include midline spinous processes and symmetrical pedicles.

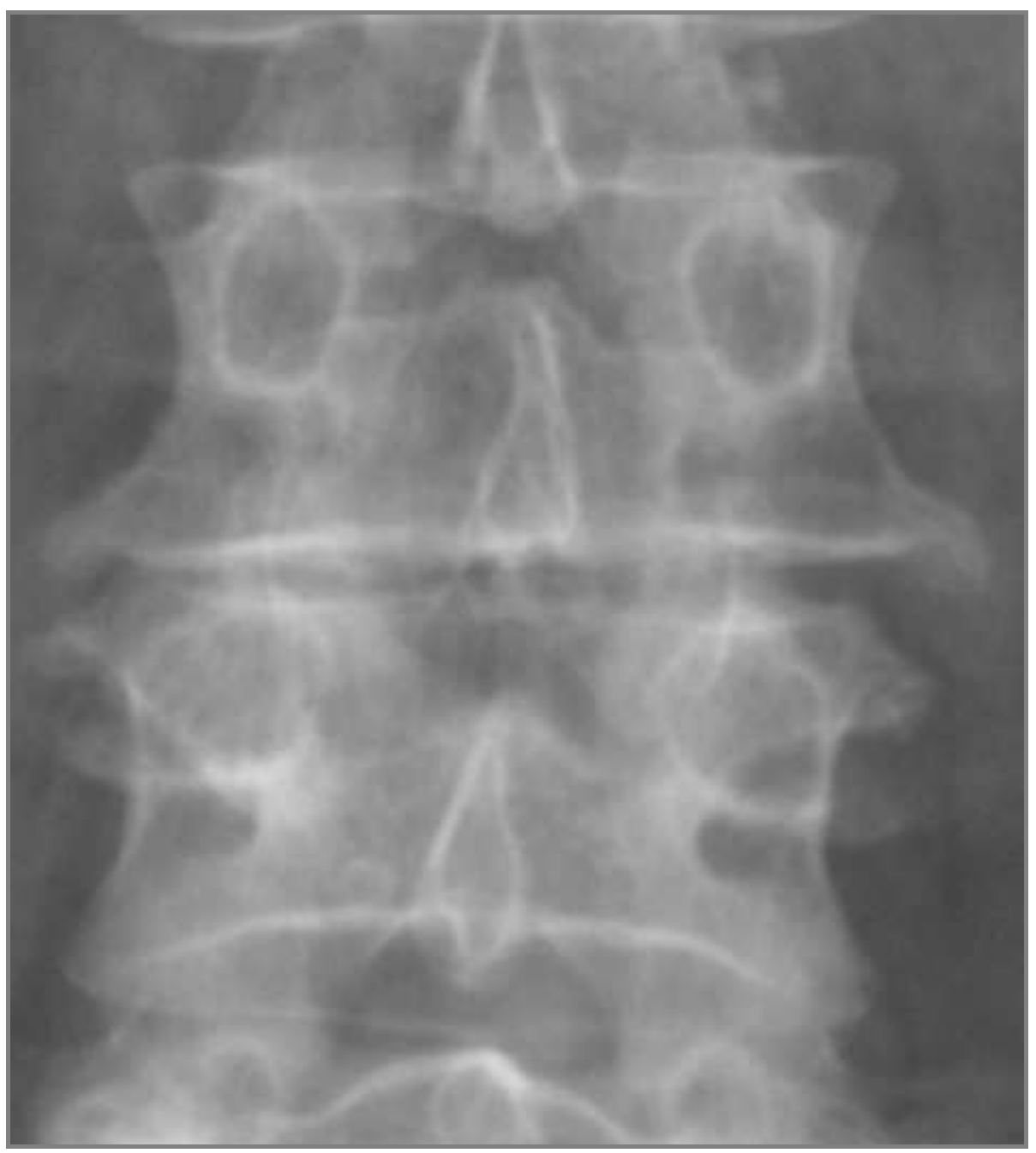

Fig. 16. True A/P image with spinous process centered and pedicles approximating their anatomic location at the endplate. Notice no "double endplate" shadow. 
The table is flexed to open up the space between the rib cage and the iliac crest (Figure 17). Once again, patient positioning is crucial to success and ensuring the patient is positioned such that the spine will "open up" after the table is flexed is essential. The surgeon must work perpendicular to the floor and parallel to the disc space at all times to avoid inadvertent vascular or neural injury. Proper fluoroscopic aligment and meticulous attention to this principal will help avoid migration of instrumentation that may lead to vascular or neural injury.

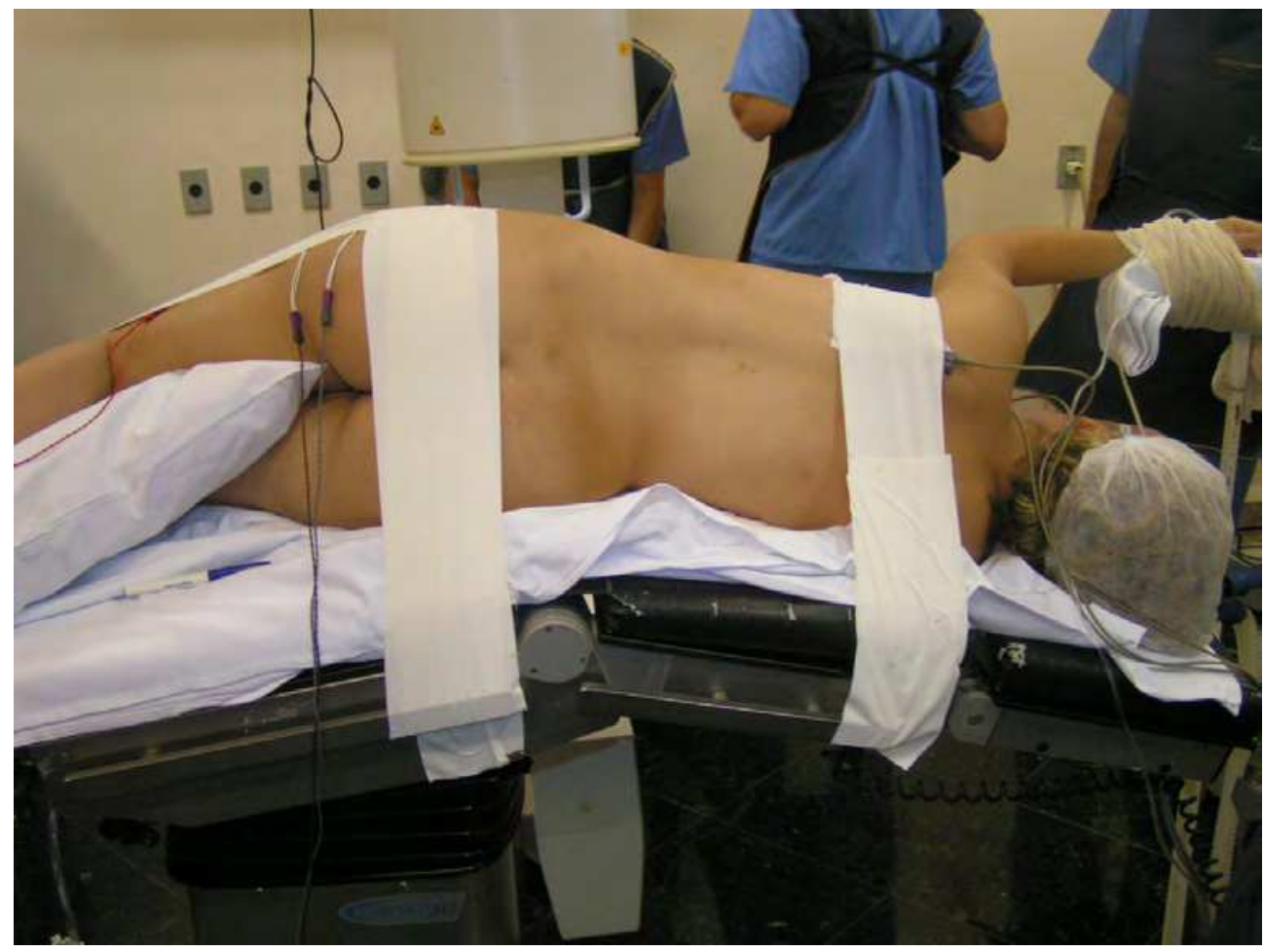

Fig. 17. Flexing the table after patient has been secured.

After an AP image has been obtained, the c-arm is rotated to obtain the lateral image. Once again, the $\mathrm{c}$ arm must be perpendicular to the floor. This helps to maintain a straight, updown orientation and trajectory of all instruments being passed in and out of the disc. Failure to maintain a strict up-down orientation can result in serious vascular or neurologic injury caused by inappropriate trajectory. To obtain the true lateral image, the table can be adjusted in the "trendelenberg" fashion by reflexing the table head up. Indications of a true lateral projection include: linear endplates, linear posterior cortex, and superimposed pedicle (Figure 18). 


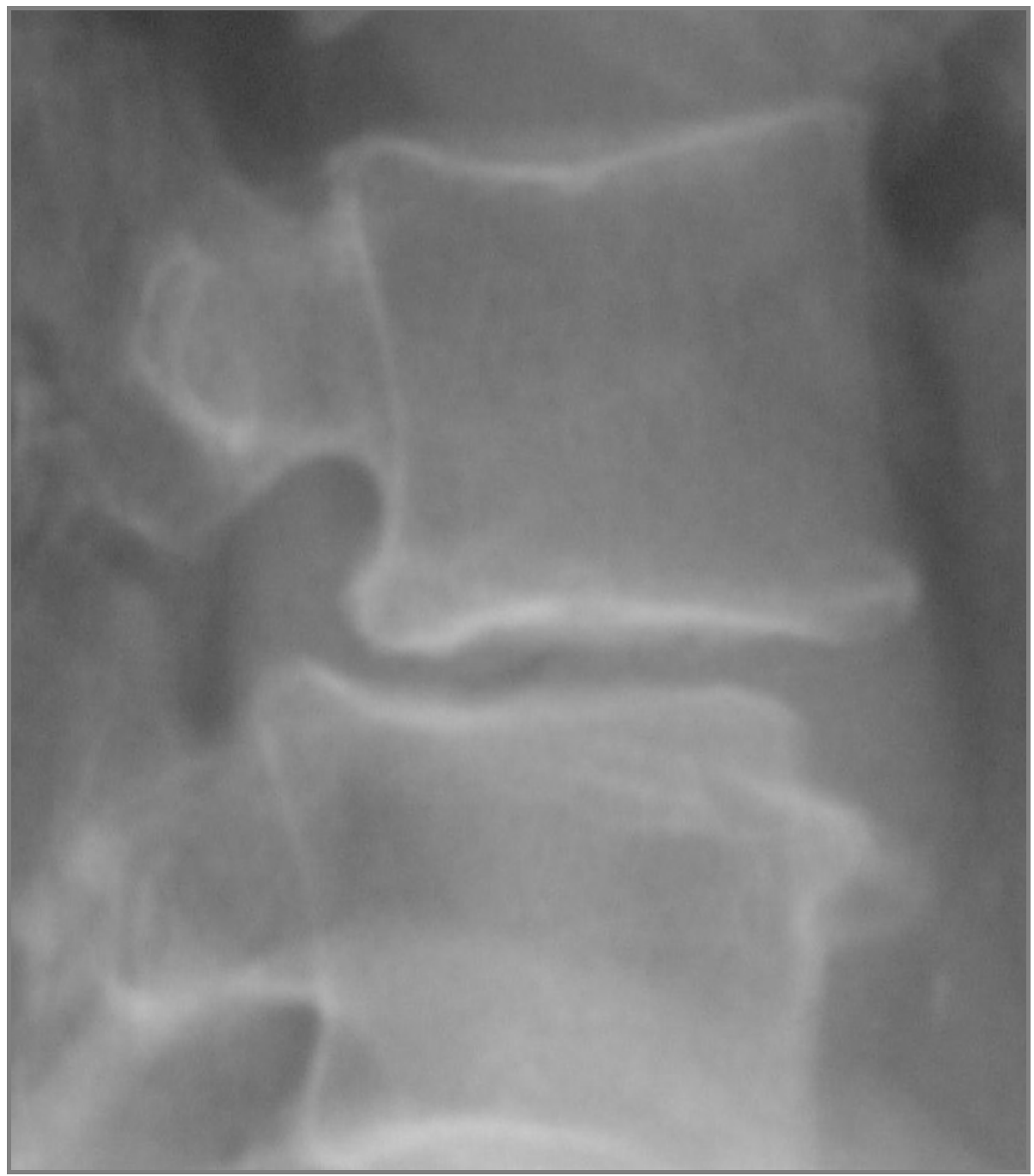

Fig. 18. True lateral image. Notice no "double pedicle" shadows. The disc space of interest is marked on AP and lateral views. 


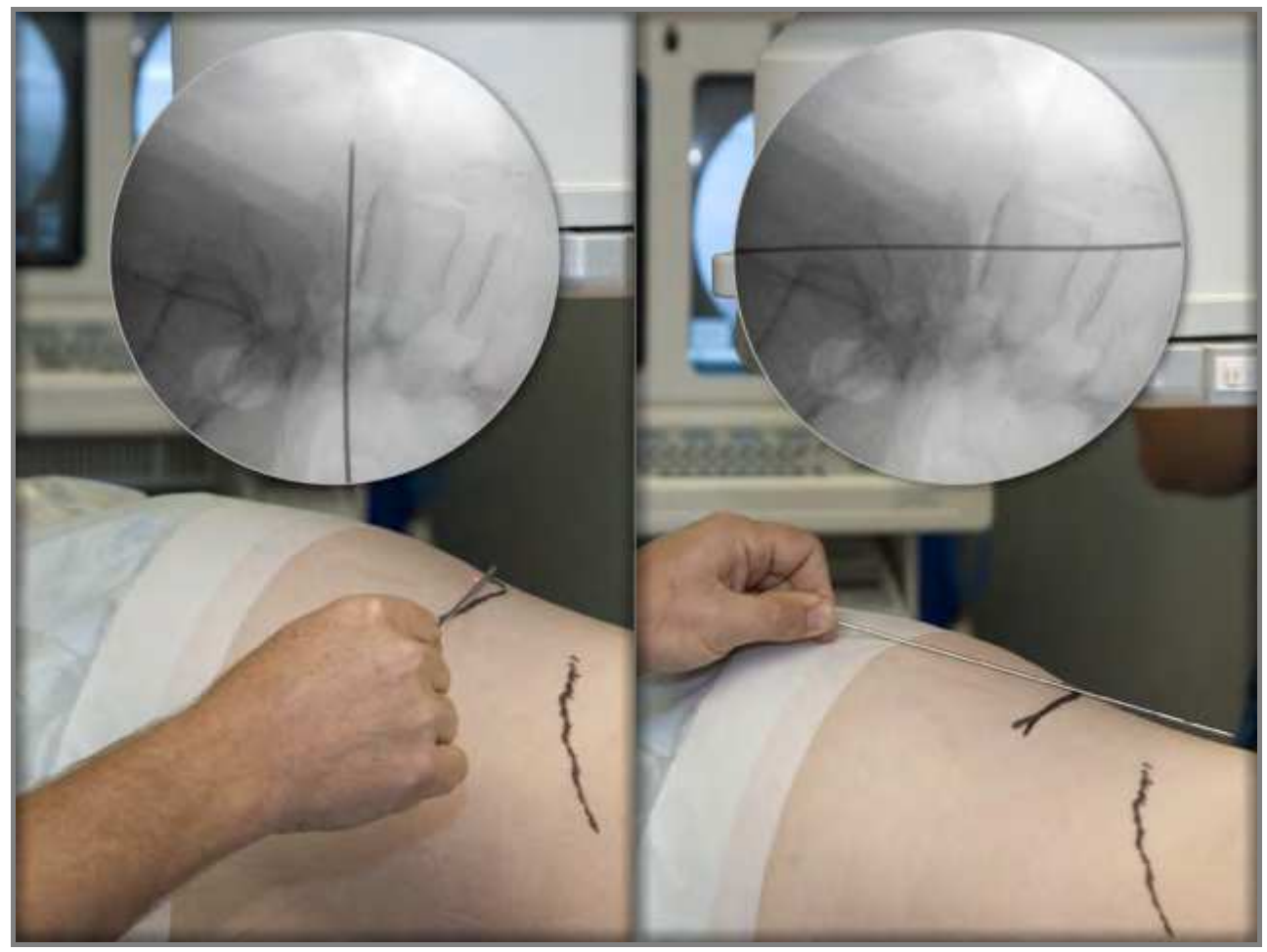

Fig. 19. Localizing the target prior to incision. Notice the first marker is marking the disc space and its orientation, and the second marker is located on the "safe zone" where the disc will be accessed.

After the patient is prepped and draped in the usual sterile fashion, one begins accessing the retroperitoneal space. The incision is based on the intersection of the $\mathrm{K}$ wires placed during $\mathrm{AP}$ and lateral localization(Figure 19). The mark is typically just lateral to the erector spinae muscles (Figure 20). An incision is made and through the posterolateral incision, the subcutaneous tissue layers are dissected using blunt scissors and findger dissection. After passing through the abdominal musculature; using a loss of resistance to guage depth results in an indication that the retroperitoneal space has been reached. A finger is passed into the retroperitoneal space and in a gentle sweeping motion is used to ensure that the peritoneum is released anteriorly, and to ensure that the abdominal contents have been mobilized forward. At our institution, we typically use a single incision and work through a incision between the intermusclular septum just lateral to the junction of the erector spinae musculature, the quadrates lumborum and the psoas. 


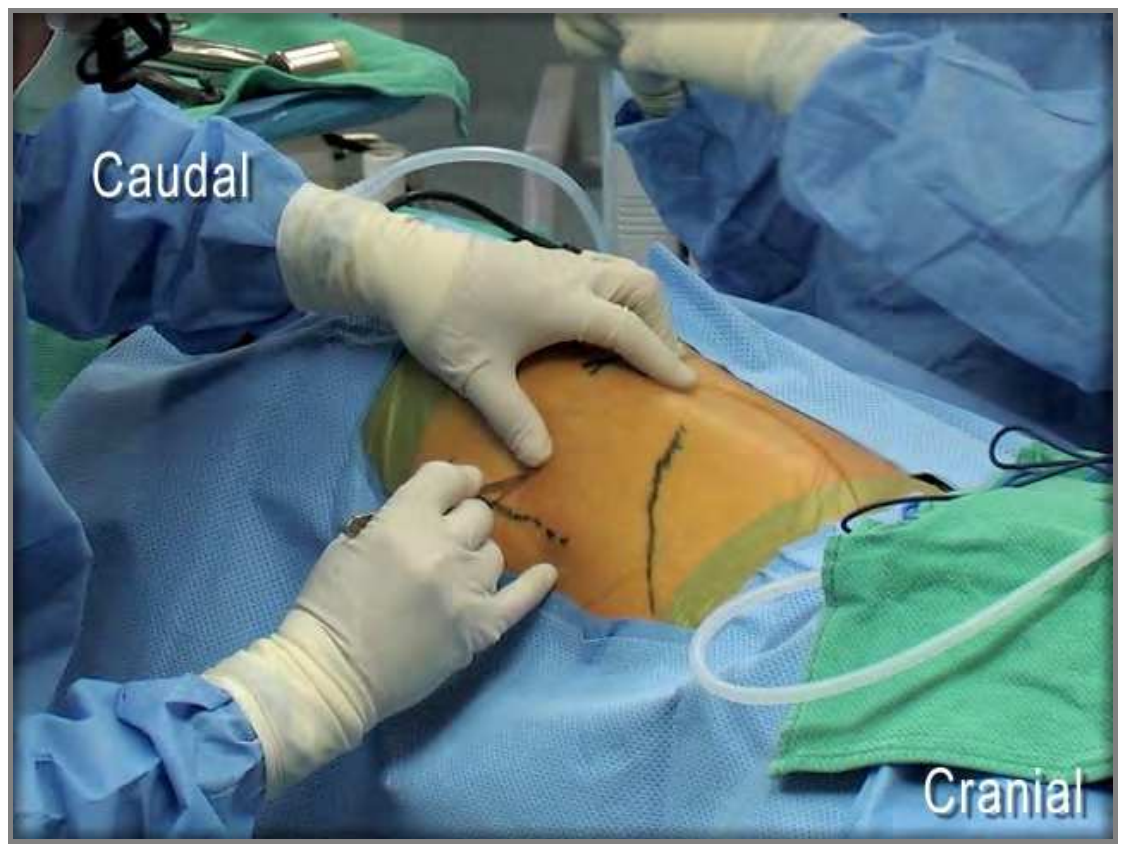

Fig. 20. The incision is made just lateral the erector spinae muscles.

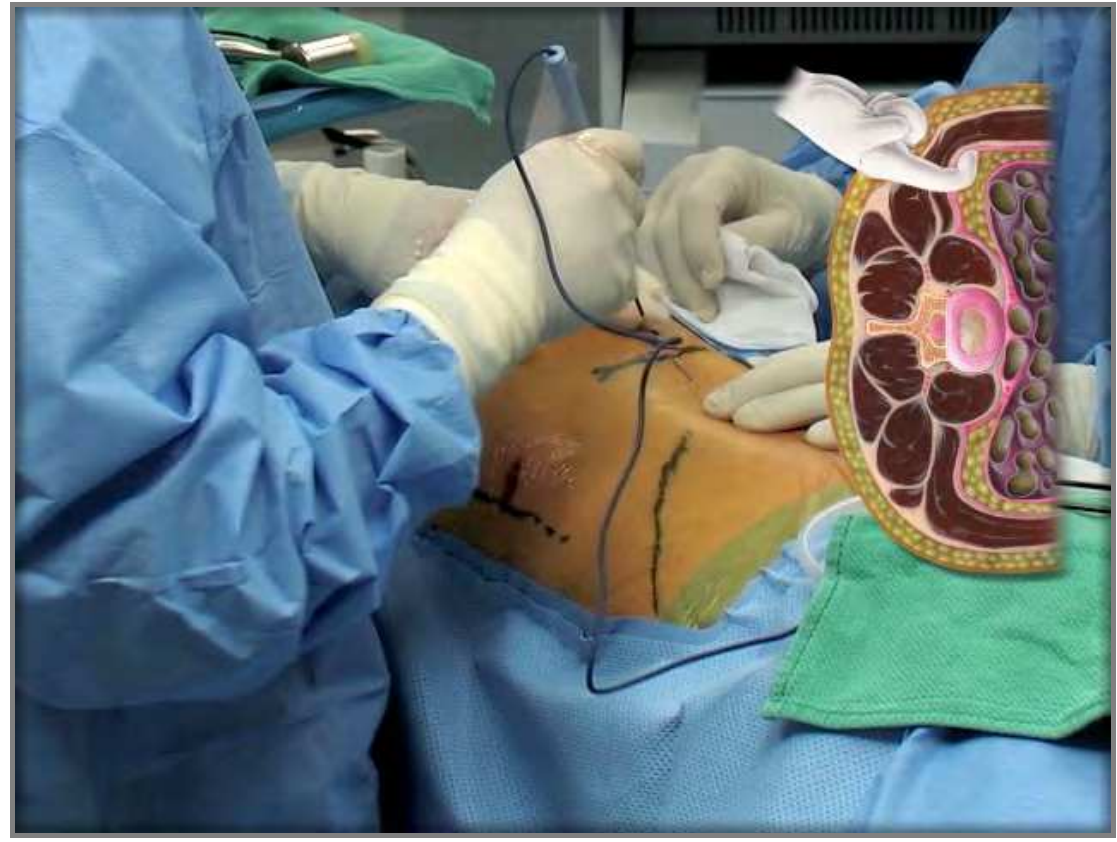

Fig. 21. Locating the point through which the dilators will be passed. 
When the peritoneal space is encountered, the surgeon palpates for the psoas muscle using the anterior tip of the transverse process as a landmark for identification. After locating the psoas muscle, the index finger is passed under the abdominal wall to lie directly underneath the lateral skin mark ensuring the abdominal contents are free from passage of the dilators. A second incision is made at this point through which the initial dilator will be passed(Figure 21). The first of sequential dilators is then connect to the neuromonioring system and then passed through the incision to inside the retroperitoneal space where the index finger will guide it onto the psoas muscle.

Once the initial dilator contacts the psoas muscle, and image is obtained using the intraopeartive c-arm fluoroscopy unit in the lateral position(Figure 22). The ideal location for the intial dilator on imaging is the center (or just posterior to the center) of the disc space. With the neuromonitoring unit in place, the fibers of the psoas muscle are split using blunt dissection with the initial dilator. The dilator is slowly advanced through the psoas in the Detection mode to identify and avoid nerves of the lumbosacral plexus. If the dilator approaches a nerve, it is slowly rotated 360 degrees to determine the location of the nerve. A higher stimulation threshold indicates that the nerve is on the distal side of the tip. In which case, the dilator is removed, then reoriented and a new path through the psoas is taken.

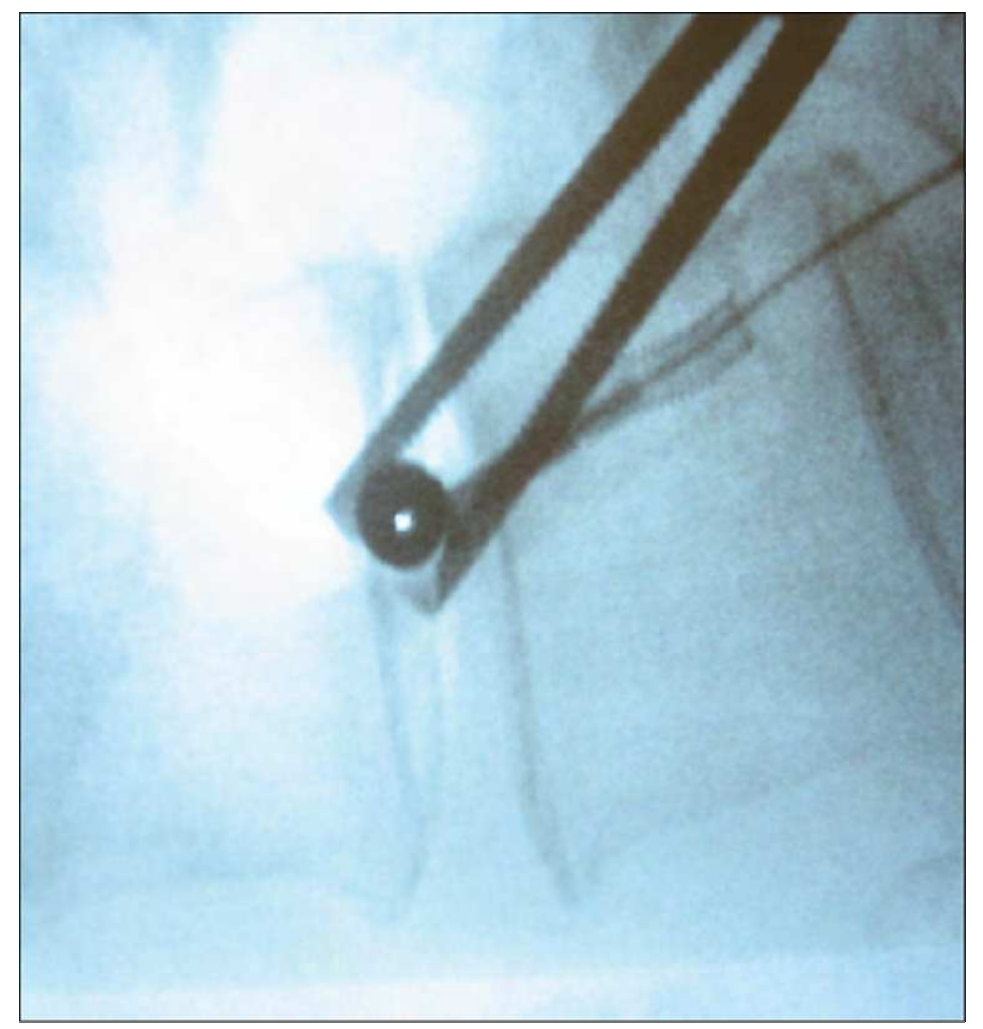

Fig. 22. The initial dilator is seen resting on the surface of the psoas muscle and appears to be in a safe location. 
The retractor is then assembled with the appropriate length blades and inserted over the dilators. The retractor can also be connected to the neuromonitoring system and stimulated as it is inserted (Figure 23). Once inserted, initial retractor depth can be confirmed with imaging. Two attachment points allow migration of the blades. A center attachment ensures that the blades open only anterior to that position, and attachment to the posterior point of connection ensure that the blades open only posterior. Care must be taken to ensure then plades don't compress neural elements against the transverse process. Illumination is achieved via the light cables down the blades of the retractor.

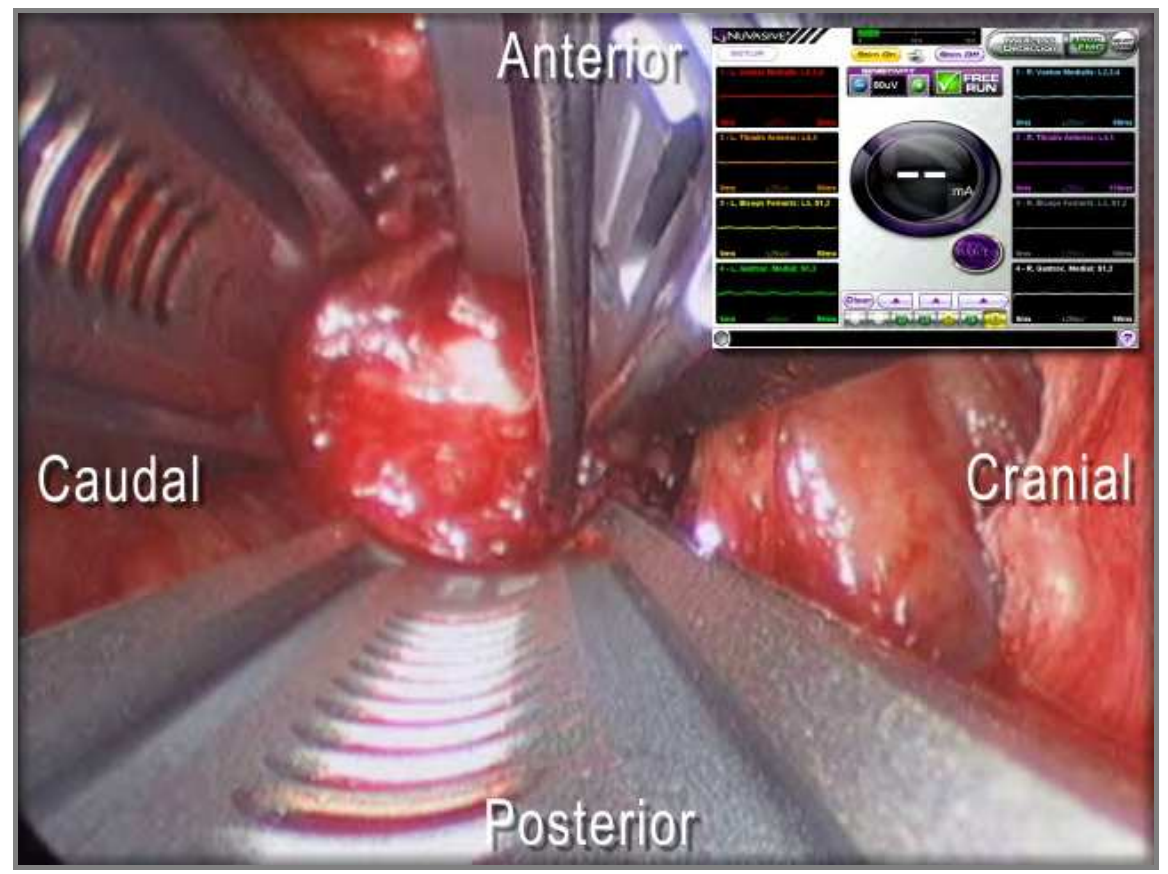

Fig. 23. View through the retractor system after passing through the posas muscle.

The neuromonitoring probe is then used to palpate the field exposed by the retractors to ensure no neural elements are within the operative field. Distal exposure can be achieved by using the blade rotation wrenches to gain optimal access to the disc space. At this point, fixation shims can be added to the retractor construct for additional stabilization. Addition of a stabilizing shim is recommended in revision surgeries, presence of a high riding crest at L4/5, or ribs at L1/2. Before placement of shims, one must identify where it will engage, visually check the area for nerves and segmental vessels, and test for nerves with the neuromonitoring probe.

\subsection{Discectomy}

Once the operative corridor has been established, the disc space can be prepared. After performing an annulotomy (at least $18 \mathrm{~mm}$ to accommodate implant), the disc space can be prepared using a combination of Rongeurs, Currettes, and Rasps. Contralateral annular 
release is imperative to the procedure to achieve proper coronal alignment. The can be safely performed by passing a Cobb elevator along both superior and inferior endplates completely through the contralateral annulus (Figures 24-25). This allows placement of an implant on the ring apophysis bilaterally.

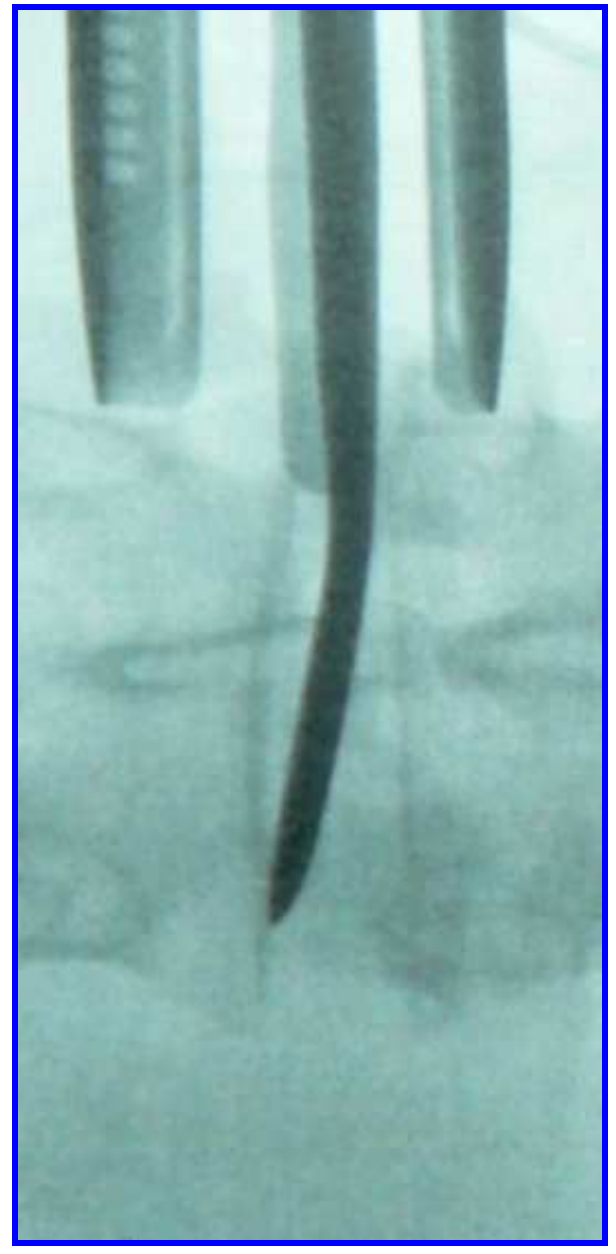

Fig. 24. Preparation of the disc space with Cobb elevator. 


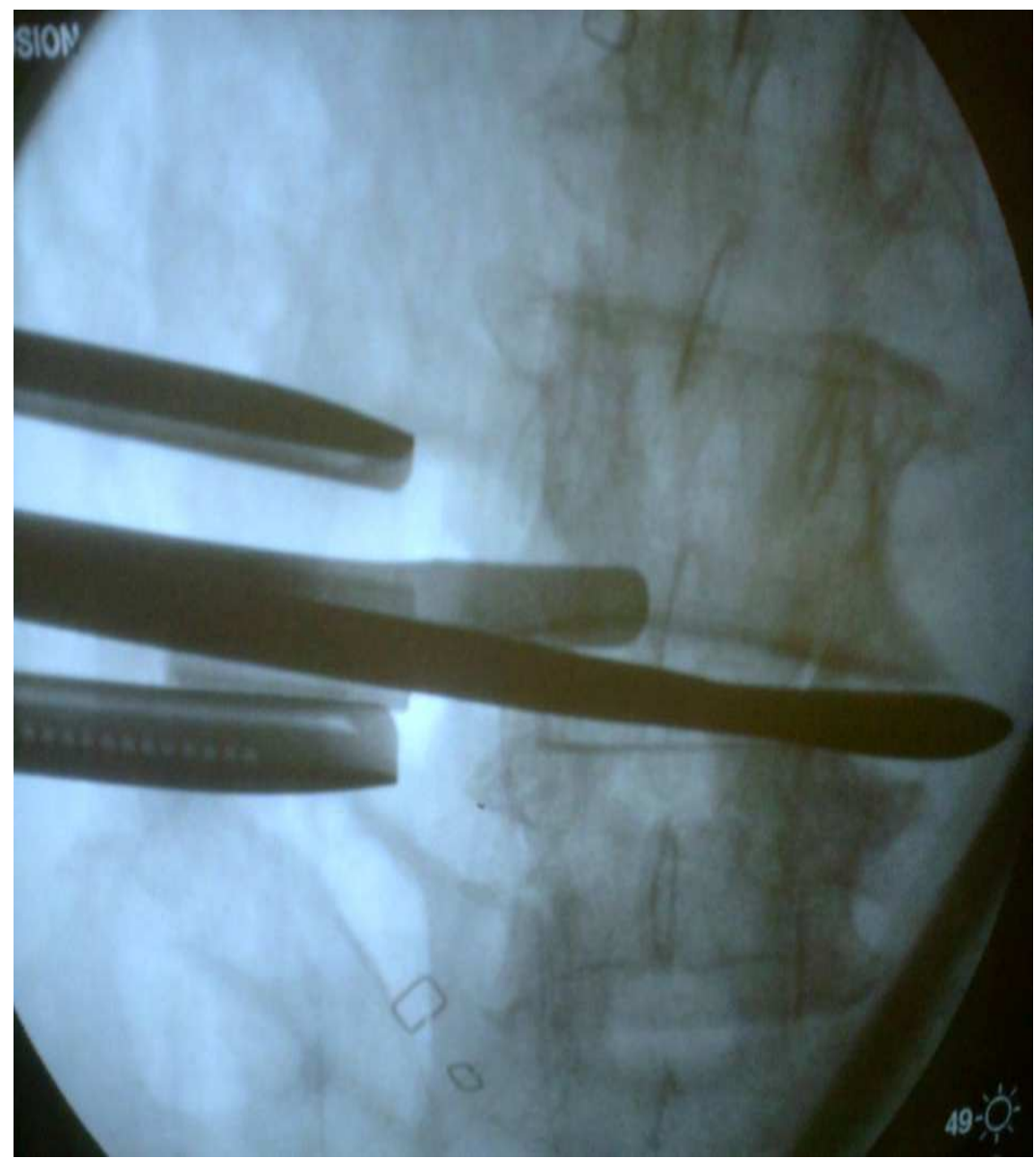

Fig. 25. Contralateral annular release with Cobb elevator. This is crucial for appropriate graft placement and restoration of coronal balance.

\subsection{Grafting}

After the discectomy has been performed and the endplates have been prepared, the next step is to choose an appropriately sized implant. A benefit of the lateral approach is the ability to place a large implant that engages the densest areas of endplate support (Figures 26-27). The implant length should thus span the ring apophysis and align with the lateral borders of the endplates on an AP image. The height of the implant should be chosen on basis of adequate disc height restoration without placing excessive $s$ train on the anterior longitudinal ligament or the endplates. Reappoximation of saggital alignment can be achieved by choosing a lordotic graft or via a more central to anterior placement of the implant. Restoration of disc height also indirectly decompresses the foramen and centrally via corrections in disc height, sagittal and coronal alignment and anterior and lateral listhesis. 


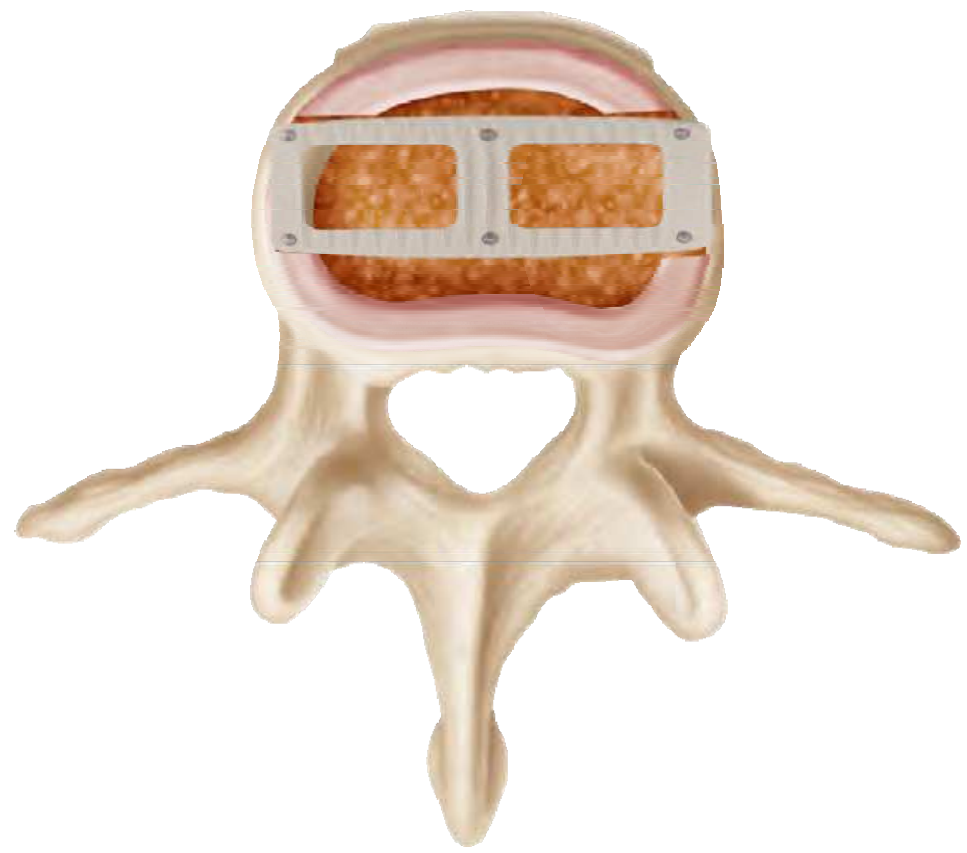

Fig. 26. Artists illustration of placement of graft demonstrating wide footprint and spanning the ring apophysis and areas of maximum structural support.

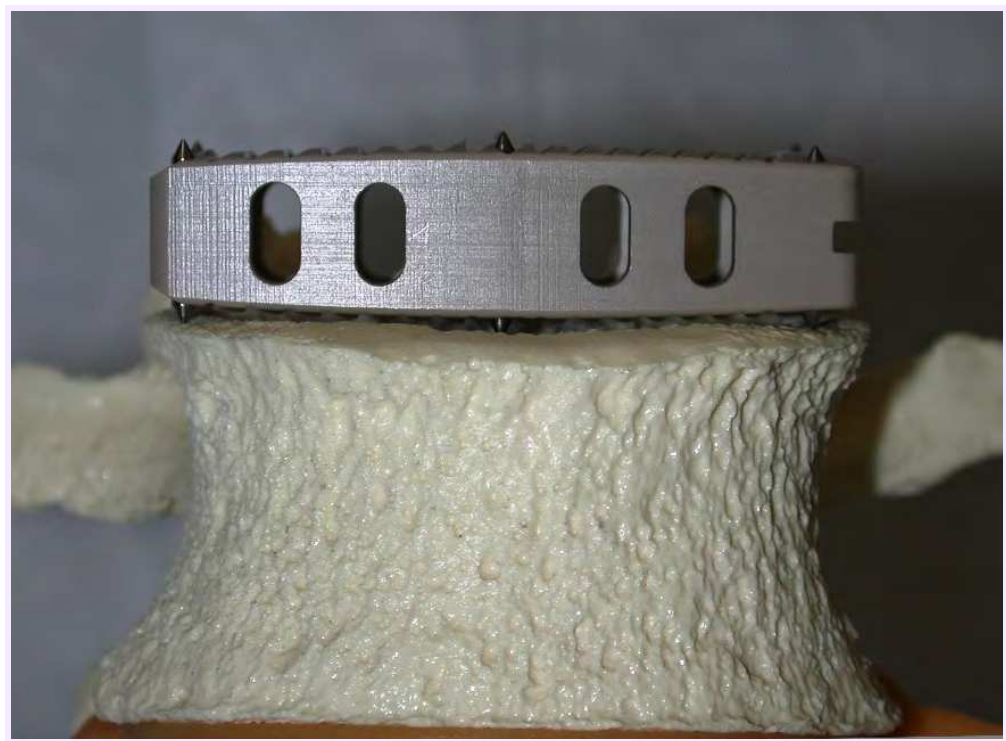

Fig. 27. A/P view of interbody graft on model shows graft spanning the areas of densest cortical bone. 
The distractor and dilators are used to gauge the appropriate sized trial which is then impacted into the disc space under fluoroscopic guidance. Once an appropriate sized trial is placed, its position is verified with AP and lateral fluoroscopy. An implant is chosen, then filled with graft material and or a biological adjuvant (rh-BMP, Medronic Sofamor-Danek, Memphis, TN). The implant is then impacted into the disc space under AP fluoroscopy. Once a trial has been placed, its location is confirmed under AP and lateral fluoroscopy prior to positioning the implant. The ideal position is centered across the disc space from a medial-lateral perspective, and in the anterior to medial third of the disc space from an anterior to posterior perspective (Figure 28).

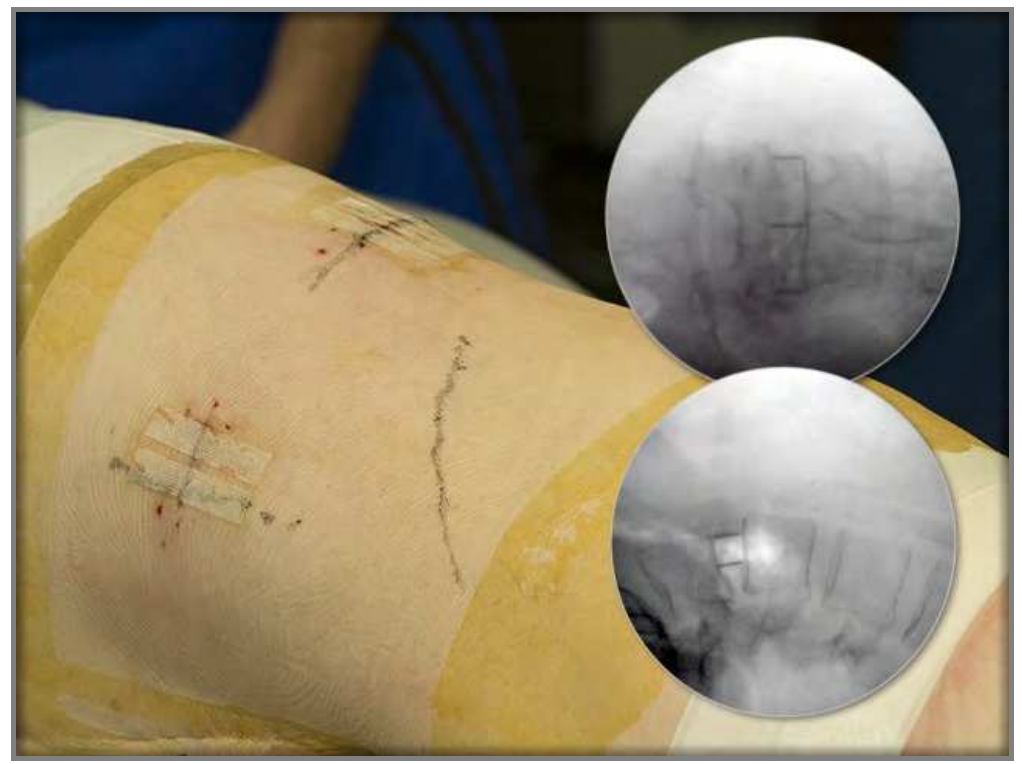

Fig. 28. A/P and lateral radiographs showing ideal graft positioning at conclusion of procedure.

\subsection{Closing/postoperative}

After conclusion of the procedure, the bladed retractors are removed and the soft tissues are inspected for any bleeding in the posas muscle or disc space. The wound is closed in layers paying meticulous attention to detailed wound closure. It is helpful to reflex the bed to a more anatomically correct position to facilitate wound closure in a tensionless fashion. Supplemental posterior instrumentation is added as needed.

Postoperative pain for the lateral incision tends to be minimial, however there are some transient side effects to expect, and these should be discussed with the patient during the preoperative office visits. Tenderness with hip flexion on the operative side is common and resolves spontaneously. Eight to $10 \%$ of patients experience some initial psoas weakness which typically resolves within 1-2 weeks. Seven transpsoas outcome studies have described sensory abnormalities in $0-30 \%$ of patients immediately after surgery. Complete resolution typically occurs by a year. From our own series, $50 \%$ of patients with new sensory 
abnormalities recover within 90 days, and nearly all within a year. There were low rates of patients who continued to report thigh numbness $(7 \%)$ and pain $(5.5 \%)$ beyond one year. Meticulous surgical technique and use of intraoperative monitoring can help avoid some complications. In general we avoid poor patient position, excessive passes of the intial dilator ("wanding") through the posas, and avoiding monopolar electrocautery. We encourage early ambularion, and use neurontin or imipramine for painful postoperative dysesthesias.

\subsection{Case considerations}

The patient is a 46 year old active male with axial low back pain, no leg pain, and no prior history of surgery. Physical examination revealed normal motor strength with no functional deficits. Femoral and straight leg testing did not produce radicular pain.

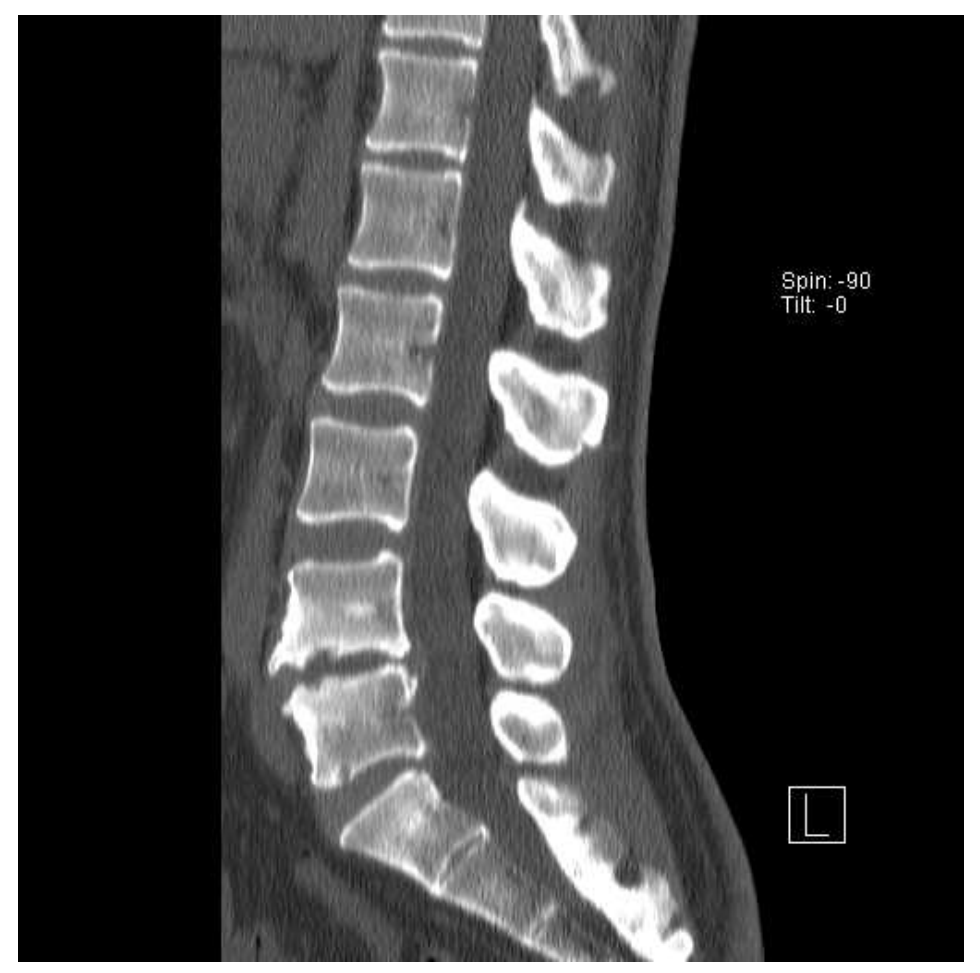

Fig. 29. CT of lumbar spine with saggital reconstruction showing advanced disc degeneration. 


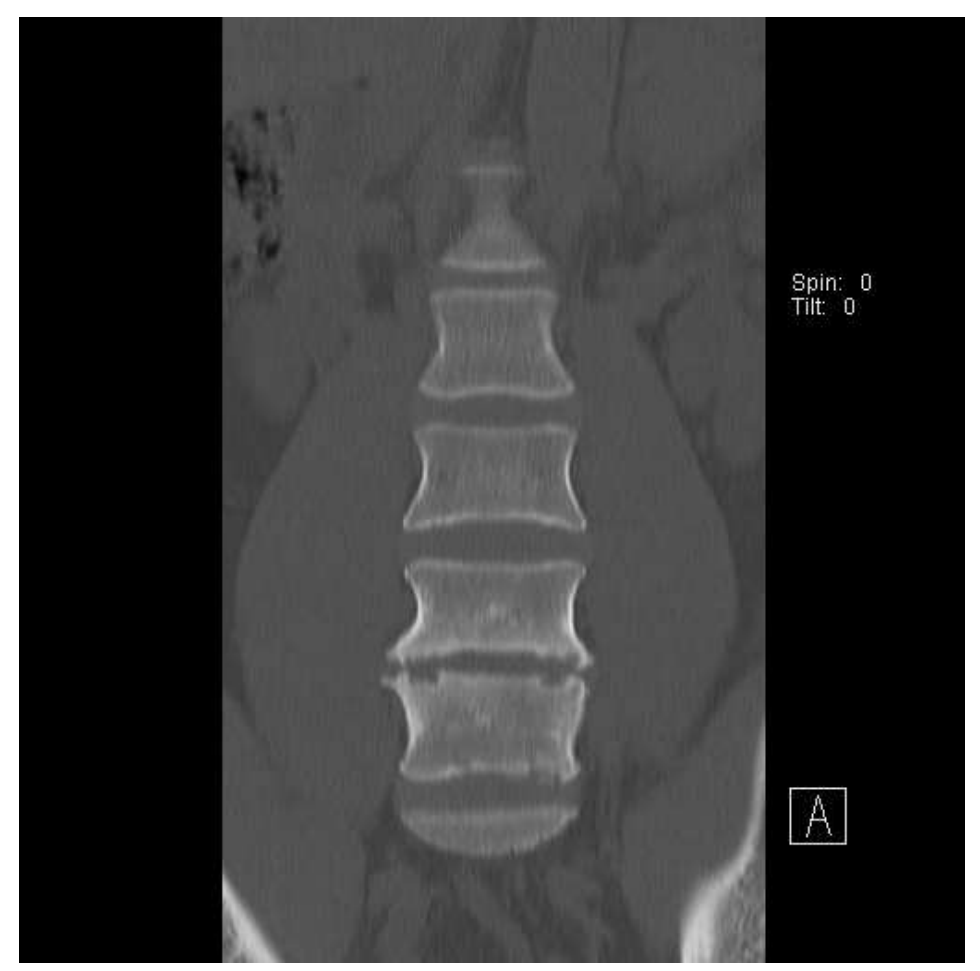

Fig. 30. CT of lumbar spine with coronal reconstruction showing advanced disc degeneration.

CT of the lumbar spine with saggital reconstruction demonstrated endplate changes consistent with sclerotic adaptations of advanced disc degeneration (Figures 29-30). MRI (not shown) showed loss of T2 signal intensity in the disc space, no significant protrusions or annular tears, but a broad based collapse of the posterior annulus toward the canal.

Surgical options were discussed with the patient after he had failed an adequate trial of conservative management. The use of spinal fusion for DDD has be found to beneficial for many patients ${ }^{18}$. However, even with a successful posterior fusion, a number of patients contine to have pain from micromotion of the collapsed disc. The addition of an interbody graft increases the stability of the construct and can be performed via a midline posterior approach as a PLIF or TLIF, or anterior via and ALIF. The surgical goal was stabilization of the affected level, to restore height and to avoid over distraction of the facets. We offered the patient a lateral interbody fusion. 


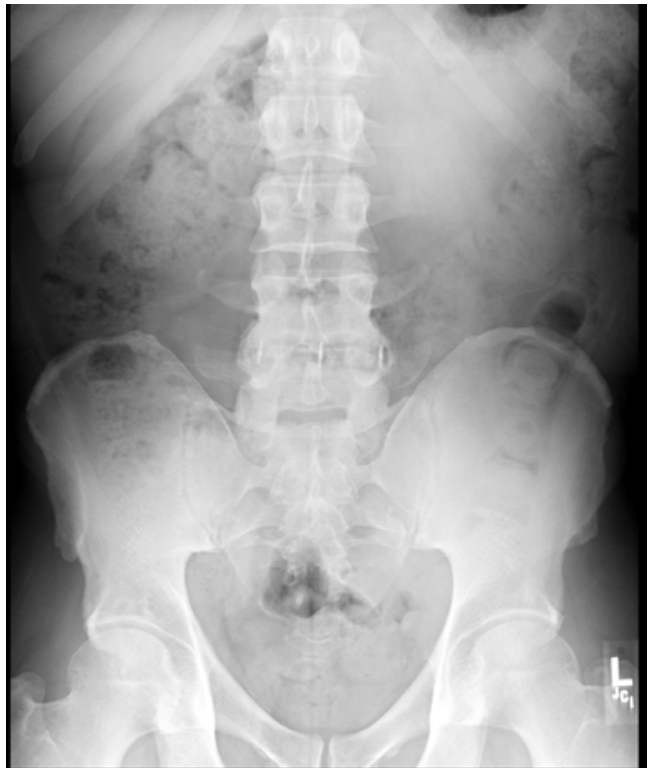

Fig. 31. Post operative A/P radiograph showing stand alone lateral interbody fusion. Note the preservation of coronal balance and restoration of disc space height.

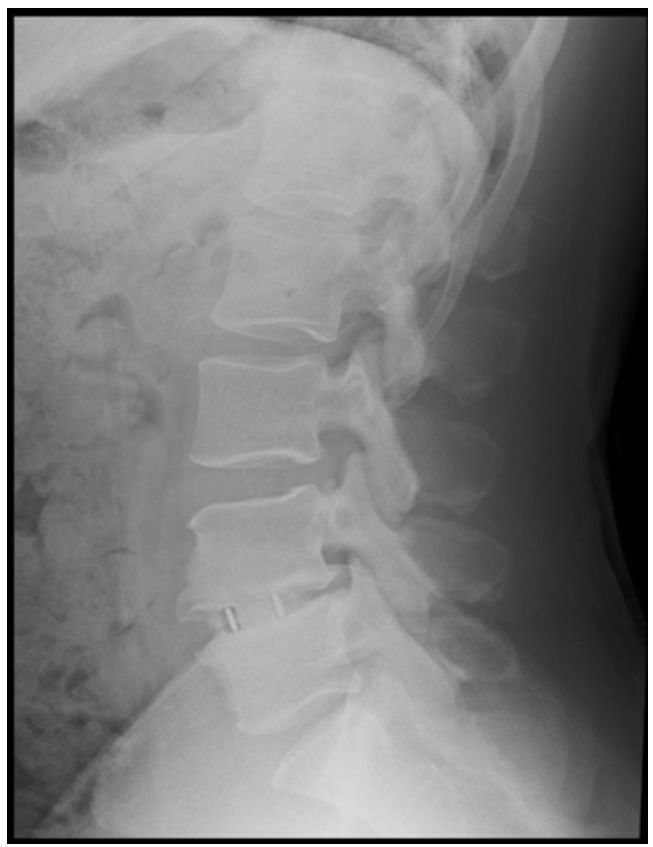

Fig. 32. Post operative lateral radiograph of stand alone lateral interbody fusion. Notice the preservation of lordosis, restoration of foramenal volume and disc space height. 


\section{Case one:}

An 18 year old female fell from a two story roof and presented to the emergency room with ASIA C quadriplegia from an L2 burst fracture(Figures 33-34).

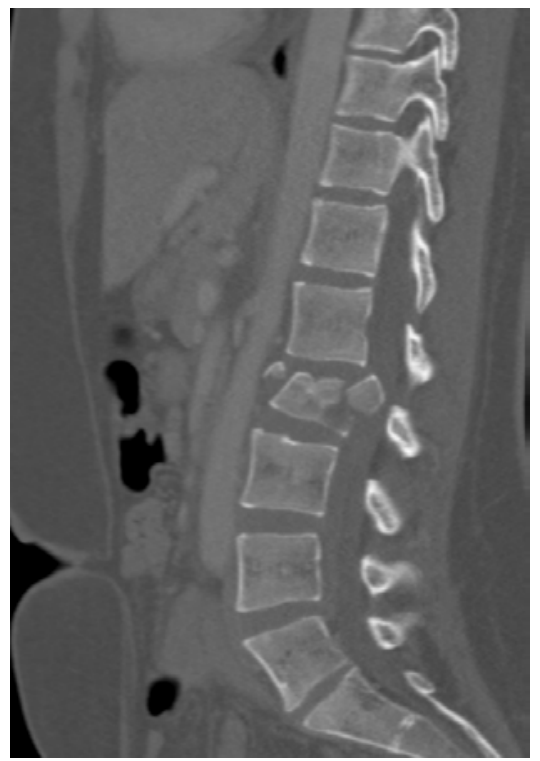

Fig. 33. CT of lumbar spine with saggital reconstruction showing L2 burst fracture with retropulsed fragments.

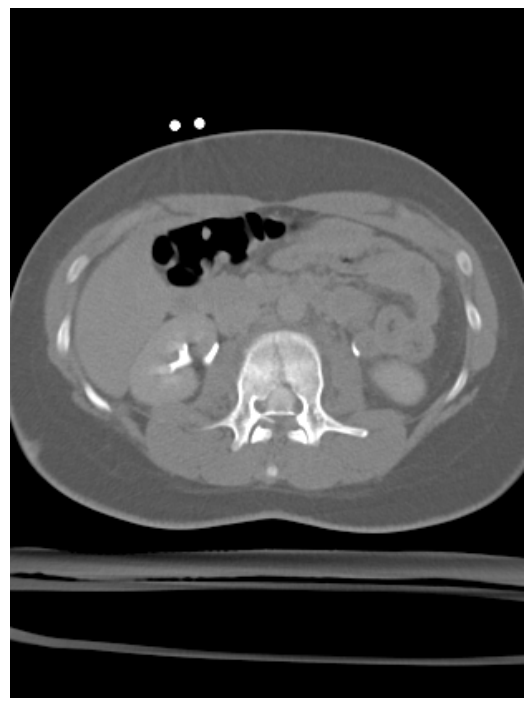

Fig. 34. Axial CT scan through L2 burst fracture showing retropulsed fragments and fractured vertebral body. 
The patient underwent a L2 corpectomy via an XLIF approach and was fitted with an expandable titanium cage. The construct was supplemented by percutaneous pedicle screw fixation (Figures 35-38).

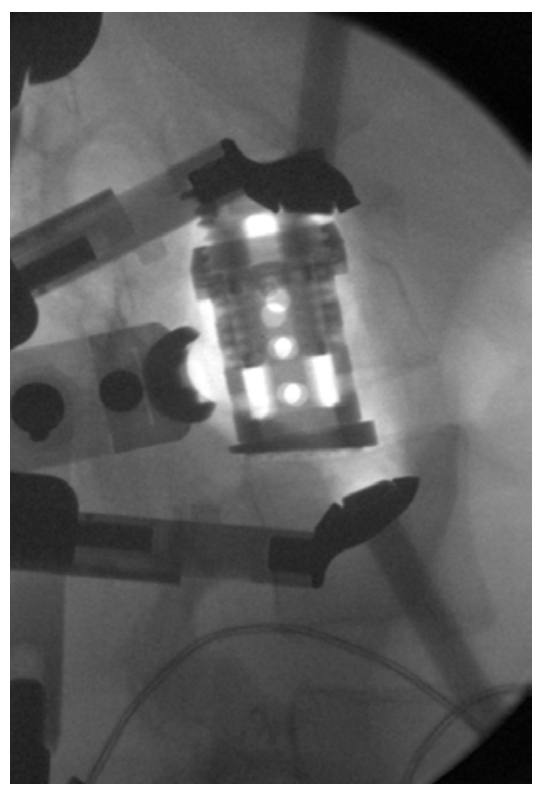

Fig. 35. Intraopeartive lateral C arm fluoroscopic image of expandable cage being deployed. Notice the adequate space provided by via a minimally invasive approach.

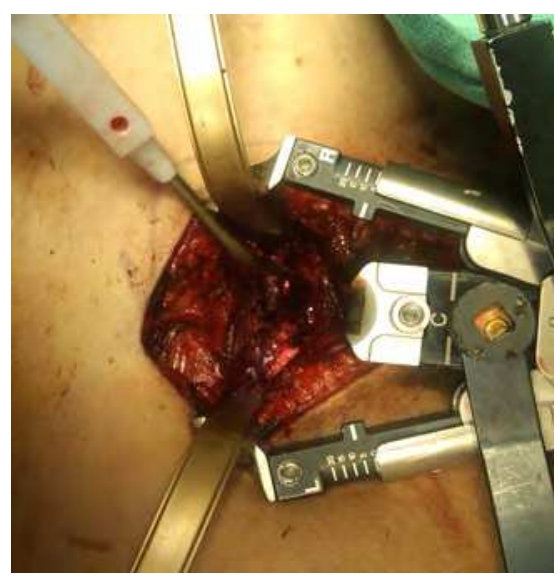

Fig. 36. View of the incision and position of the retractor system. 


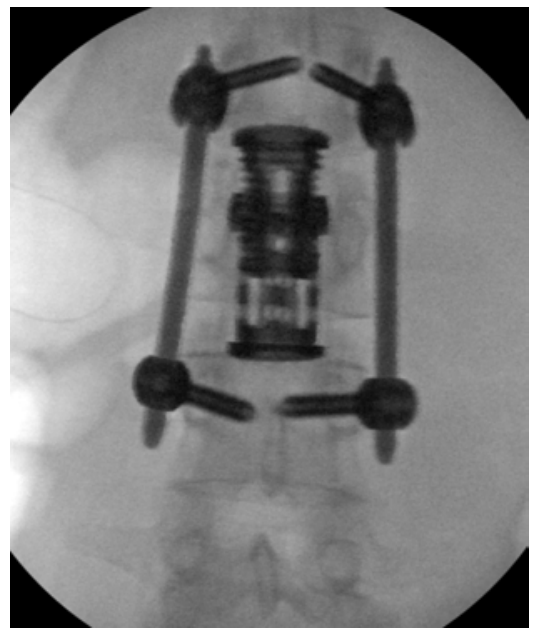

Fig. 37. Post operative A/P flurouscopic image of expandable cage and percutaneous pedicle screws.

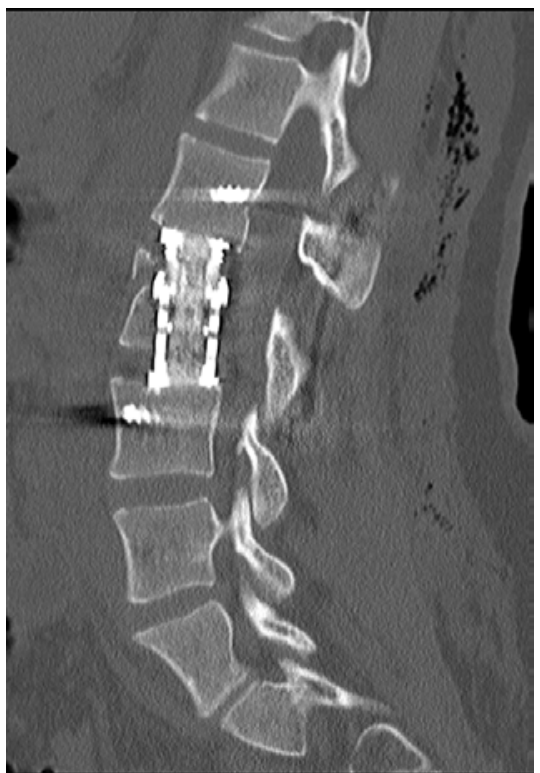

Fig. 38. Post operative CT of lumbar spine with saggital reconstruction showing complete decompression of canal via a lateral retroperitoneal transpsoas approach.

When performing corpectomies for trauma the surgical goal is immediate decompression which is often hampered by the need for an access surgeon. With the XLIF approach, this is eliminated. Additionally, in anterior approaches there is concern about posterior migration of fragments injuring the neural elements. By using an XLIF approach, and working within the retractors that border the adjacent vertebral segments as well as the thecal sac, the risk of 
posterior fragment migration is decreased. The XLIF approach allows decompression of the neural elements as well as restoration of anterior column support, is safe and reproducible.

Case two:

A 79 year old female presented with intractable back pain. She gives a history of having a spinal epidural abscess three years prior that was treated with multi-level laminectomies. She is currently neurologically intact, but requires a walker to stand up straight (Figures 39-42).

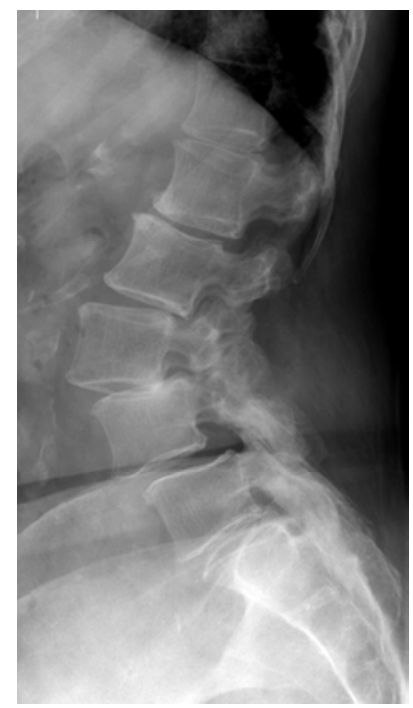

Fig. 39. Lateral plain radiograph demonstrating post-laminectomy deformity.

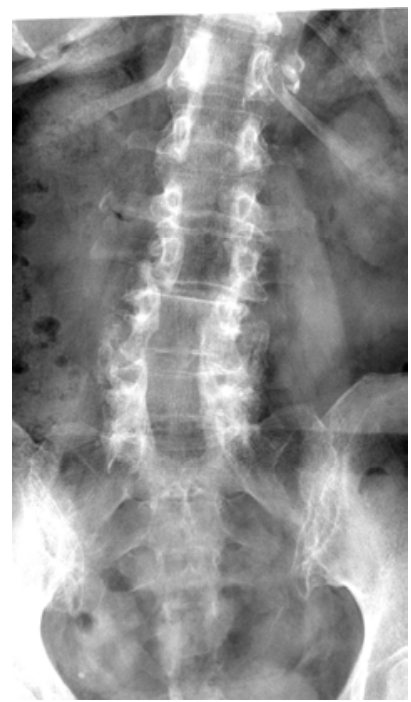

Fig. 40. A/P radiograph demonstrating coronal deformity in addition to saggital deformity. 


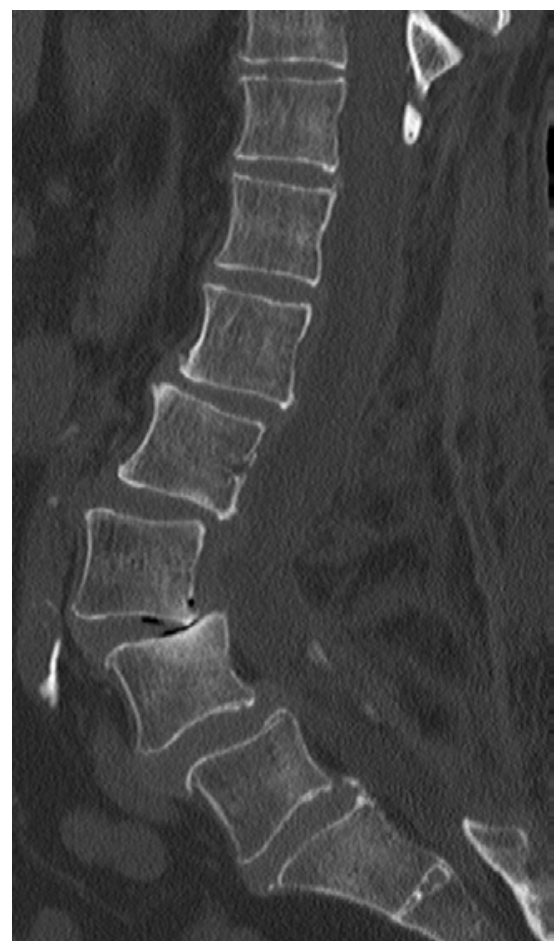

Fig. 41. CT of lumbar spine with saggital reconstruction demonstrating the degree of postlaminectomy deformity.

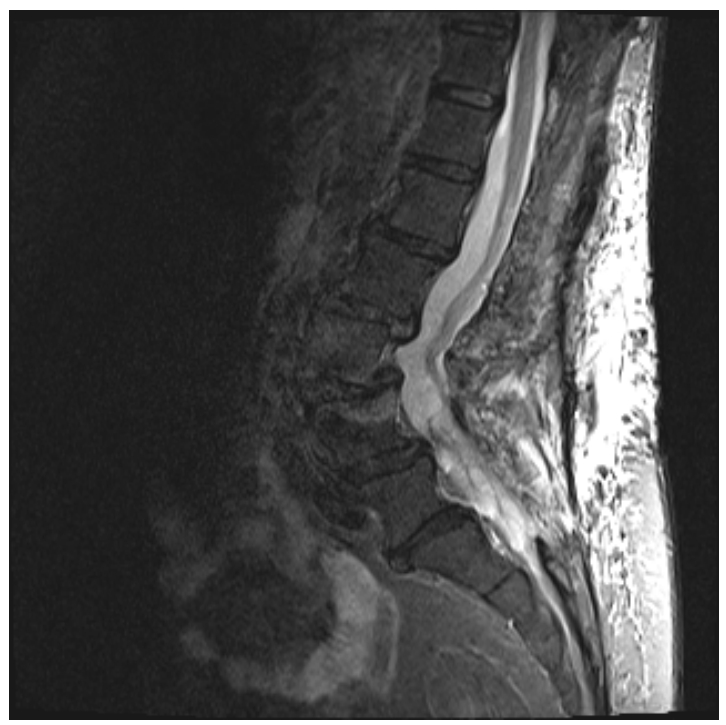

Fig. 42. Saggital T2 weighted MRI of same patient. 
Traditional treatments for iatrogenic deformity are associated with long operative times, high blood loss, and extended hospitalization. As surgical magnitude increae, morbidity, complication and recovery times increase substantially. The lateral retroperitoneal transposas approach results in minimal dissection and stripping result in less surgical time and less bleeding. The bilateral annular relase allows straightening and derotation of the spine. Placing large interbody implants realigns the endplates, restores disc heights and indirectly decompresses the neural elements. Saggital balance can be restored through the placement of lordotic grafts in the anterior disc space (Figures 43-44). The lateral retroperitoneal transposas approach offers a more tolerable surgical option for patients with complex deformity and significant medical comorbidities.

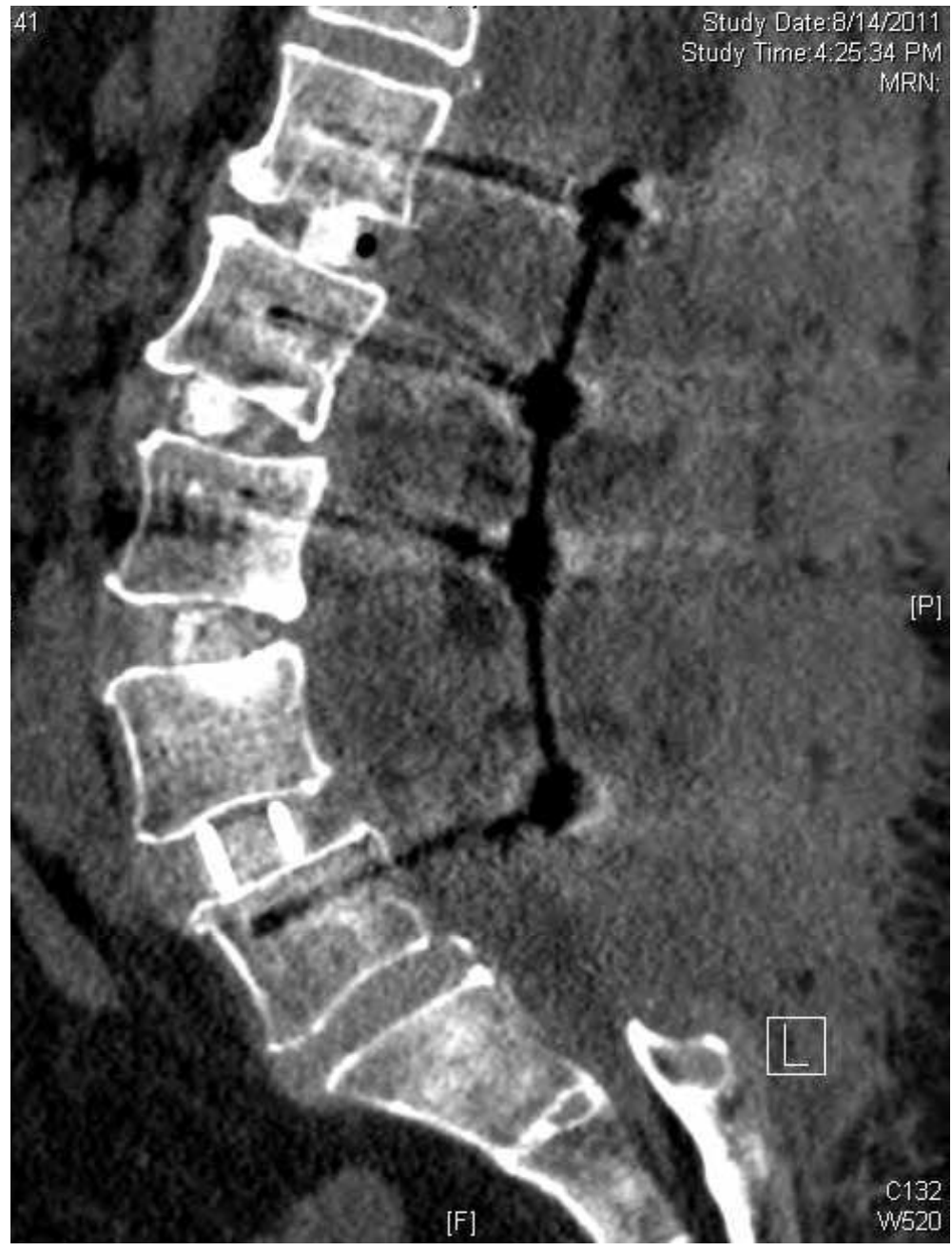

Fig. 43. Post operative CT of lumbar spine with saggital reconstruction demonstrating restoration of saggital balance. 


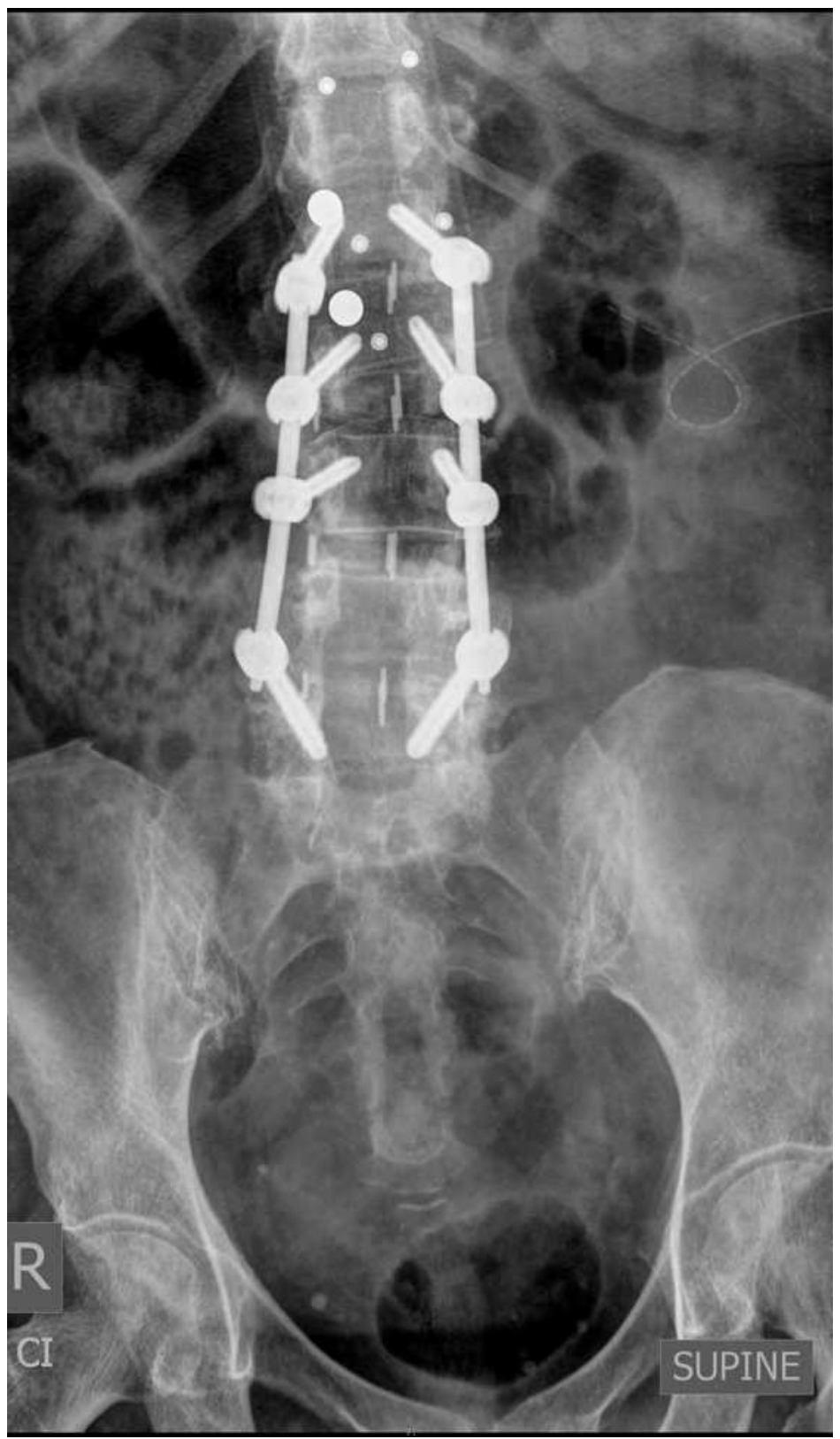

Fig. 44. Post operative A/P radiograph demonstrating restoration of coronal balance.

\section{Acknowledgment}

The authors would like to thank NuVasive (San Diego, CA) for figures 1-8, 13-15, 17, 19-28. 


\section{References}

[1] Burns B. An Operation for Spondylolisthesis. Lancet. 1933 1933;1(23):33.

[2] Bohm H, Harms J, Donk R, Zielke K. Correction and stabilization of angular kyphosis. Clin Orthop Relat Res. Sep 1990(258):56-61.

[3] Bradford DS. Adult scoliosis. Current concepts of treatment. Clin Orthop Relat Res. Apr 1988(229):70-87.

[4] Gertzbein SD, Court-Brown CM, Jacobs RR, et al. Decompression and circumferential stabilization of unstable spinal fractures. Spine (Phila Pa 1976). Aug 1988;13(8):892895.

[5] Cloward RB. The treatment of ruptured lumbar intervertebral discs by vertebral body fusion. I. Indications, operative technique, after care. J Neurosurg. Mar 1953;10(2):154-168.

[6] Faciszewski T, Winter RB, Lonstein JE, Denis F, Johnson L. The surgical and medical perioperative complications of anterior spinal fusion surgery in the thoracic and lumbar spine in adults. A review of 1223 procedures. Spine (Phila Pa 1976). Jul 15 1995;20(14):1592-1599.

[7] Regan JJ, Aronoff RJ, Ohnmeiss DD, Sengupta DK. Laparoscopic approach to L4-L5 for interbody fusion using BAK cages: experience in the first 58 cases. Spine (Phila Pa 1976). Oct 15 1999;24(20):2171-2174.

[8] Baker JK, Reardon PR, Reardon MJ, Heggeness MH. Vascular injury in anterior lumbar surgery. Spine (Phila Pa 1976). Nov 1993;18(15):2227-2230.

[9] Christensen FB, Bunger CE. Retrograde ejaculation after retroperitoneal lower lumbar interbody fusion. Int Orthop. 1997;21(3):176-180.

[10] Hackenberg L, Liljenqvist U, Halm H, Winkelmann W. Occlusion of the left common iliac artery and consecutive thromboembolism of the left popliteal artery following anterior lumbar interbody fusion. J Spinal Disord. Aug 2001;14(4):365-368.

[11] Hannon JK, Faircloth WB, Lane DR, et al. Comparison of insufflation vs. retractional technique for laparoscopic-assisted intervertebral fusion of the lumbar spine. Surg Endosc. Mar 2000;14(3):300-304.

[12] McAfee PC, Bohlman HH, Yuan HA. Anterior decompression of traumatic thoracolumbar fractures with incomplete neurological deficit using a retroperitoneal approach. J Bone Joint Surg Am. Jan 1985;67(1):89-104.

[13] Mayer HM. A new microsurgical technique for minimally invasive anterior lumbar interbody fusion. Spine (Phila Pa 1976). Mar 15 1997;22(6):691-699; discussion 700.

[14] McAfee PC, Regan JJ, Geis WP, Fedder IL. Minimally invasive anterior retroperitoneal approach to the lumbar spine. Emphasis on the lateral BAK. Spine (Phila Pa 1976). Jul 1 1998;23(13):1476-1484.

[15] Bergey DL, Villavicencio AT, Goldstein T, Regan JJ. Endoscopic lateral transpsoas approach to the lumbar spine. Spine (Phila Pa 1976). Aug 1 2004;29(15):1681-1688.

[16] Ozgur BM, Aryan HE, Pimenta L, Taylor WR. Extreme Lateral Interbody Fusion (XLIF): a novel surgical technique for anterior lumbar interbody fusion. Spine J. Jul-Aug 2006;6(4):435-443.

[17] White AA, Panjabi MM. Clinical biomechanics of the spine. 2nd ed. Philadelphia: Lippincott; 1990.

[18] Nachemson A, Zdeblick TA, O'Brien JP. Lumbar disc disease with discogenic pain. What surgical treatment is most effective? Spine (Phila $\mathrm{Pa}$ 1976). Aug 1 1996;21(15):1835-1838. 


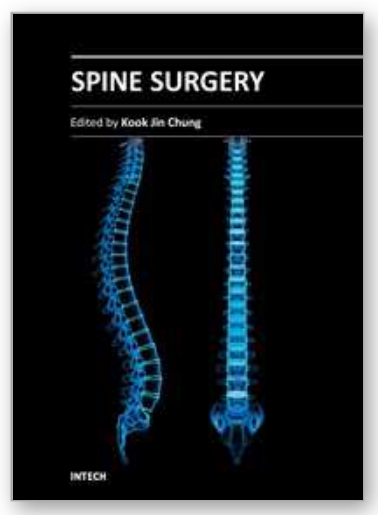

\author{
Spine Surgery \\ Edited by Dr. Kook Jin Chung
}

ISBN 978-953-51-0469-8

Hard cover, 148 pages

Publisher InTech

Published online 28, March, 2012

Published in print edition March, 2012

"Spine Surgery" is an authoritative and didactic textbook on the various fields of spine. It is written by many authors, internationally honorable experts to share their opinions with you. The chapters cover from anatomy of spine, spinal imaging technique, biology of spine, bone graft substitute, minimally invasive spinal surgery to even spinal deformity. It has many up to date results to help readers including university graduate students, medical instrumentation developers, and medical professionals including orthopaedic and neurosurgeons, rehabilitative professionals. The readers are provided with precious information and valuable guide in your daily practice.

\title{
How to reference
}

In order to correctly reference this scholarly work, feel free to copy and paste the following:

Brian Hood and Steven Vanni (2012). Minimally Invasive Extreme Lateral Trans-Psoas Approach to the Lumbar Spine: Applications and Techniques, Spine Surgery, Dr. Kook Jin Chung (Ed.), ISBN: 978-953-510469-8, InTech, Available from: http://www.intechopen.com/books/spine-surgery/minimally-invasiveanterolateral-spinal-fusion-indications-technique-and-outcomes

\section{INTECH}

open science | open minds

\section{InTech Europe}

University Campus STeP Ri

Slavka Krautzeka 83/A

51000 Rijeka, Croatia

Phone: +385 (51) 770447

Fax: +385 (51) 686166

www.intechopen.com

\section{InTech China}

Unit 405, Office Block, Hotel Equatorial Shanghai

No.65, Yan An Road (West), Shanghai, 200040, China

中国上海市延安西路65号上海国际贵都大饭店办公楼405单元

Phone: +86-21-62489820

Fax: $+86-21-62489821$ 
(C) 2012 The Author(s). Licensee IntechOpen. This is an open access article distributed under the terms of the Creative Commons Attribution 3.0 License, which permits unrestricted use, distribution, and reproduction in any medium, provided the original work is properly cited. 